\title{
Magnetic hydroxyapatite: a promising multifunctional platform for nanomedicine application
}

\author{
This article was published in the following Dove Press journal: \\ International Journal of Nanomedicine \\ Number of times this article has been viewed
}

\author{
Sudip Mondal' \\ Panchanathan Manivasagan' \\ Subramaniyan Bharathiraja' \\ Madhappan Santha \\ Moorthy' \\ Hye Hyun Kim ' \\ Hansu Seo ${ }^{2}$ \\ Kang Dae Lee $^{3}$ \\ Junghwan $\mathrm{Oh}^{1,2}$ \\ 'Marine-Integrated Bionics Research \\ Center, ${ }^{2}$ Department of Biomedical \\ Engineering and Center for Marine- \\ Integrated Biotechnology (BK2I \\ Plus), Pukyong National University, \\ ${ }^{3}$ Department of Otolaryngology - \\ Head and Neck Surgery, Kosin \\ University College of Medicine, \\ Busan, Republic of Korea
}

Correspondence: Junghwan Oh Department of Biomedical Engineering and Center for Marine-Integrated Biotechnology (BK2I Plus), Pukyong National University, Busan 485I3, Republic of Korea

Tel +82 5 I 629577 I

Fax +825I 6295779

Email jungoh@pknu.ac.kr

\begin{abstract}
In this review, specific attention is paid to the development of nanostructured magnetic hydroxyapatite (MHAp) and its potential application in controlled drug/gene delivery, tissue engineering, magnetic hyperthermia treatment, and the development of contrast agents for magnetic resonance imaging. Both magnetite and hydroxyapatite materials have excellent prospects in nanomedicine with multifunctional therapeutic approaches. To date, many research articles have focused on biomedical applications of nanomaterials because of which it is very difficult to focus on any particular type of nanomaterial. This study is possibly the first effort to emphasize on the comprehensive assessment of MHAp nanostructures for biomedical applications supported with very recent experimental studies. From basic concepts to the real-life applications, the relevant characteristics of magnetic biomaterials are patented which are briefly discussed. The potential therapeutic and diagnostic ability of MHAp-nanostructured materials make them an ideal platform for future nanomedicine. We hope that this advanced review will provide a better understanding of MHAp and its important features to utilize it as a promising material for multifunctional biomedical applications.
\end{abstract}

Keywords: hydroxyapatite, iron oxide, hyperthermia, drug delivery, tissue engineering

\section{Introduction}

The increased application of nanomaterials in our everyday work increases human interactions with nanoparticles. Since Freeman et al introduced the concept of using magnetism in medicine in the 1960s, a vast amount of research has been performed, leading to the design of several magnetic nanoparticles and vectors. ${ }^{1}$ Recent progress in the field of magnetic nanoparticles for therapeutic applications has considerably surpassed expectations. The ability to specifically target and easily recover excess or unused drugs by an external magnetic field makes these nanoparticles particularly interesting for researchers.

The key factor for magnetism solely depends on the orbital and spin motions of electrons and the in-between interactions of electrons. Magnetic materials are classified into the following five major groups according to the behavior of a material in a magnetic field: diamagnetic, paramagnetic, ferromagnetic, ferrimagnetic, and antiferromagnetic. Magnetic targeting is established on the following two key aspects: a magnetically responsive carrier and a magnetic field gradient (magnetic force) that is liable for attracting or placing magnetically responsive carriers inside a body system. Superparamagnetism is an extremely important characteristic for a magnetic material, which allows strong instant magnetization (during magnetization, all magnetic atoms align parallel to the direction of an applied magnetic field). There should be no residual magnetization (remanence) remaining after removal of the magnetic force. 
When a magnetic material is positioned in a magnetic field $H$, specific atomic moments in the material give their overall response to the magnetic induction $(B)$ :

$$
B=\mu_{0}(H+M)
$$

where $\mu_{0}$ represents the free space permeability and $M$ (magnetization) $=m / V$ which denotes the magnetic moment per unit volume. ${ }^{2}$ The force applied to a magnetic carrier with magnetic moment $\vec{m}$ is given by the following equation: ${ }^{3}$

$$
\vec{F}=(\vec{m} \cdot \nabla \vec{B}) \vec{B}
$$

where $\vec{F}=$ magnetic force, $\vec{m}=$ magnetic moment, $\vec{B}=$ magnetic field, and $\nabla \vec{B}=$ high magnetic field gradients.

The versatile fundamental characteristics of magnetic nanoparticles facilitate numerous therapeutic applications such as controlled and specific targeted drug delivery, detoxification of biological fluids, magnetic resonance imaging (MRI), cancer therapy, magnetic fluid hyperthermia, environmental application (adsorption or catalysis), and isolation of pathogens and macromolecules and as sensors. The most common types of magnetic nanoparticles are based on iron oxides. Investigations have also been performed on magnetic nanoparticles based on other dopants. Magnetic nanoparticles are broadly categorized into the following eight different categories: (1) iron oxide $\left(\mathrm{Fe}_{3} \mathrm{O}_{4}, \mathrm{Fe}_{2} \mathrm{O}_{3}\right)$;
(2) iron doped; (3) Fe and platinum co-doped; (4) barium, manganese, and $\mathrm{Fe}$ doped; (5) cobalt-ferrite $\left(\mathrm{CoFe}_{2} \mathrm{O}_{4}\right)$; (6) gadolinium-neodymium co-doped; (7) samarium $\left({ }^{153} \mathrm{Sm}\right.$ ) lexidronam and Gd incorporated; and (8) iron oxide, Fe, and copper doped. Superparamagnetic iron oxide nanoparticles exhibit superior characteristics compared with other magnetic compounds, such as less toxicity, high magnetic saturation, and easy fabrication, which attracts a great deal of attention.

All the magnetic materials used for different application purposes, especially for the biomedical application, have some merits and demerits (Table 1). A demerit of magnetic materials such as $\mathrm{Nd}, \mathrm{Gd}$, and $\mathrm{Sm}$ is that they need large external fields and controlled environment to influence. Materials with efficient magnetization and great susceptibility are preferred for applications such as drug targeting and magnetic separation. Transition metals (like cobalt) possess a potential magnetic property; however, owing to their toxicity, these types of materials are less used in biological research. Manganese, another suitable metal, has been used as a bonereconstructing and bone loss-inhibiting agent. However, manganese substitution does not affect the magnetic properties of composite materials. Different magnetic nanomaterials have been produced for different functional aspects. In biomedical applications, nanoparticles could not be directly used in the body system. They require some precautions such as surface modification by means of coating, before their medicinal application.

\begin{tabular}{|c|c|c|c|c|}
\hline S no & Materials & Advantages & Disadvantages & Study \\
\hline I & Iron oxide HAp & $\begin{array}{l}\text { Magnetic hyperthermia, drug delivery application, } \\
\text { superparamagnetic behavior, etc. }\end{array}$ & $\begin{array}{l}\text { Core shell HAp-coated iron oxide synthesis } \\
\text { is difficult and associated with multiple steps }\end{array}$ & $\begin{array}{l}\text { Trandafir } \\
\text { et } \mathrm{al}^{4}\end{array}$ \\
\hline 2 & Fe-doped HAp & $\begin{array}{l}\text { Magnetic hyperthermia, drug delivery } \\
\text { application, etc. }\end{array}$ & $\begin{array}{l}\text { Fe-HAp exhibits very low crystallinity and a } \\
\text { structural coherence at the nanometer length } \\
\text { scale together with very low thermal stability }\end{array}$ & $\begin{array}{l}\text { Tampieri } \\
\text { et } \mathrm{al}^{5}\end{array}$ \\
\hline 3 & $\begin{array}{l}\text { Fe and Pt co-doped } \\
\text { HAp }\end{array}$ & $\begin{array}{l}\text { Good catalytic activity, used in sensors, high } \\
\text { stability, etc. }\end{array}$ & Limited biological application due to toxicity & $\begin{array}{l}\text { Tseng } \\
\text { et } \mathrm{al}^{6}\end{array}$ \\
\hline 4 & Mn- and Fe-doped & $\begin{array}{l}\text { Useful for hyperthermia applications, to treat } \\
\text { bone cancer, MRI contrast agent }\end{array}$ & $\begin{array}{l}\text { Manganese substitution does not affect the } \\
\text { magnetic properties in composite materials }\end{array}$ & $\begin{array}{l}\text { Pon-On } \\
\text { et al }\end{array}$ \\
\hline 5 & $\begin{array}{l}\text { Cobalt-ferrite } \\
\left(\mathrm{CoFe}_{2} \mathrm{O}_{4}\right) \text {-doped HAp }\end{array}$ & Bioimaging property, MRI contrast agent & Metal toxicity to biometabolism & $\begin{array}{l}\text { Petchsang } \\
\text { et al }{ }^{8}\end{array}$ \\
\hline 6 & Gd-Nd co-doped & $\begin{array}{l}\text { Good luminescent property for bioimaging. } \\
\text { Electrical conductivity of HAp is improved because } \\
\text { of the high polarizability of } \mathrm{Nd} \text { (III) and Gd (III) }\end{array}$ & $\begin{array}{l}\text { Need large external fields and controlled } \\
\text { environment to influence }\end{array}$ & $\begin{array}{l}\text { Syamchand } \\
\text { and Sony }{ }^{9}\end{array}$ \\
\hline 7 & $\begin{array}{l}\text { Samarium }\left({ }^{153} \mathrm{Sm}\right) \\
\text { lexidronam and } \mathrm{Gd} \\
\text { incorporated }\end{array}$ & $\begin{array}{l}\text { Used for bioimaging specially for SPECT/MRI } \\
\text { dual-imaging probe }\end{array}$ & $\begin{array}{l}\text { Need large external fields and controlled } \\
\text { environment to influence }\end{array}$ & Liu et $\mathrm{a}^{10}$ \\
\hline 8 & $\begin{array}{l}\text { Iron oxide, Fe- and } \\
\text { Cu-doped HAp }\end{array}$ & $\begin{array}{l}\text { Drug delivery ability, pro-osteogenic and } \\
\text { proangiogenic activities }\end{array}$ & $\begin{array}{l}\text { The size and morphology varies with different } \\
\text { dopant compositions. The solubility in water } \\
\text { media is also variable }\end{array}$ & $\begin{array}{l}\text { Kuda } \\
\text { et } \text { al }^{\prime \prime}\end{array}$ \\
\hline
\end{tabular}

Table I Advantages and disadvantages of different types of MHAp nanostructures for biomedical application

Abbreviations: MHAp, magnetic hydroxyapatite; HAp, hydroxyapatite; MRI, magnetic resonance imaging; SPECT, single-photon emission computed tomography. 


\section{Importance of coating over magnetic nanoparticles}

The issues regarding biocompatibility and toxicity limit the choice of materials for biomedical application; however, coatings may make the use of these materials feasible. Biocompatible polymers, metals, ceramics, or composites are generally used as coatings to render the materials nontoxic and nonimmunogenic. Moreover, coatings help in reducing aggregation and preventing magnetic particles from being directly exposed to the body. In addition, coatings are used as matrix for drugs, nucleotides, or genetic materials to deliver them to target sites. Different types of coatings have been employed for nanoparticles to make them suitable for different applications. These coatings and their consequent geometric structure on nanoparticles control their complete size, which also regulates the biodistribution of nanoparticles in a body system. Coatings are chosen based on their application, for example, to induce a response to inflammation, in tissue engineering, or as anticancer agents. Coated magnetic nanoparticles can bind to proteins, enzymes, nucleotides, drugs, and antibodies, and could also be directed toward a target site by an external magnetic field. ${ }^{12}$ All coating materials have some advantages and limitations (Table 2). Based on the experimental data, it was observed that polymers were the first choice of researchers as coating materials. Iafisco et al synthesized magnetic hollow micro-nanospheres $(2 \mu \mathrm{m}$ to $500 \mathrm{~nm}$ ) coated with polymeric shell of poly(L-lactic) acid for potential application as scaffolds for hard tissue regeneration as well as carriers for biomolecules. ${ }^{13}$ Taccola et al reported a single-step fast free-standing, flexible nanofilm preparation process for poly(L-lactic) acid-coated iron oxide nanocomposite for biomedical application. ${ }^{14}$ Polyacrylic acid (PAA)-coated iron oxide nanoparticles (size $\sim 9$ $\mathrm{nm}$ ) were used together with first-line anti-TB drug rifampicin in Mycobacterium as efflux inhibitors to overcome drug resistance. ${ }^{15} \mathrm{Ma}$ et al synthesized PAA-coated magnetite nanoparticles (PAA-MNPs, $246 \mathrm{~nm}$ ) and studied magnetically targeted thrombolysis with recombinant tissue plasminogen activator bound to PAA-MNPs. ${ }^{16}$ Denizot et al reported the synthesis of phosphorylcholine-coated iron oxide nanoparticles $(5 \mathrm{~nm})$ for use as MRI contrast agent. In this study, phosphorylcholine facilitated a thin-wall

Table 2 Different coating and doping materials for iron oxide nanoparticles

\begin{tabular}{|c|c|c|c|c|}
\hline S no & $\begin{array}{l}\text { Coating and } \\
\text { doping materials }\end{array}$ & Advantages & Disadvantages & References \\
\hline \multicolumn{5}{|c|}{ Polymer coatings over iron oxide } \\
\hline I & Poly (D,L-lactide) & Enhanced biocompatibility & Usually very unstable (affected with varying & 13,14 \\
\hline 2 & Polyacrylic acid & Improves bioadhesion & $\mathrm{pH}$ and temperature); agglomeration and & 15,16 \\
\hline 3 & Phosphorylcholine & Initiates coagulation & adherence property (causing toxic and & 17 \\
\hline 4 & Polyvinyl pyrrolidone & Improves functionalization & immunogenic effects); inside body system, & 18 \\
\hline 5 & Polyvinyl alcohol & Increases monodisperse particle formation & hydrodynamic flow retards its movement & $19-22$ \\
\hline 6 & Polyethylene glycol & Improves biocompatibility & (mostly dissolved in body fluids and & 23,24 \\
\hline 7 & Dextran & Biocompatible, controlling particle size and shapes & degradation due to enzyme activity) & 25,26 \\
\hline 8 & Polystyrene & $\begin{array}{l}\text { Uniform cluster formation, controlling particle size } \\
\text { and shapes }\end{array}$ & & 27 \\
\hline 9 & Starch & Biocompatible, coating material & & 28,29 \\
\hline 10 & Ethyl cellulose & Enhances drug uptake, good functional property & & 30,31 \\
\hline II & Gelatin & Natural, biocompatible & & $32-34$ \\
\hline 12 & Chitosan & Natural, biocompatible & & 35 \\
\hline 13 & Fatty acids & Terminal group functionalization, biocatalyst & & 36,37 \\
\hline 14 & Bovine serum albumin & Biocompatible & & 38 \\
\hline 15 & Folic acid & Targets cancer cells, less immunogenic & & 39 \\
\hline 16 & Insulin & Improves gene therapy & & 40 \\
\hline 17 & Liposome & Long circulatory time in body system & & 41 \\
\hline \multicolumn{5}{|c|}{ Metal and metal oxide coatings over iron oxide } \\
\hline I & Gold & Enhances optical properties and stabilization & Toxic effects, fabrication difficulties, and & 42,43 \\
\hline 2 & Silver & Enhances optical properties and antimicrobial activity & cost associated with its synthesis & 44 \\
\hline 3 & Platinum & Enhances optical and electrochemical properties & & 45 \\
\hline 4 & Zinc & Enhances magnetic property & & 46 \\
\hline 5 & $\mathrm{SiO}_{2}$ & Increases surface area and binding affinity & Increases oxidative stress and agglomerates & 47,48 \\
\hline 6 & $\mathrm{TiO}_{2}$ & Photocatalytic activity & Nonbiological application only & 49 \\
\hline 7 & $\begin{array}{l}\text { Calcium phosphate } \\
\text { coating }\end{array}$ & Biocompatible, osteoconductive & Difficult to control coating layer thickness & 50 \\
\hline 8 & Hydroxyapatite & Biocompatible, stable, osteoconductive & Difficult to control coating layer thickness & $65-107$ \\
\hline
\end{tabular}


coating over iron oxide nanoparticles. ${ }^{17}$ During the synthesis of nanomaterials, some polymers like polyvinyl pyrrolidone (PVP), polyvinyl alcohol, polystyrene, and dextran control the size, shape, and growth of nanoparticles. ${ }^{18-27}$ Liu et al used PVP as a surfactant in one-pot polyol process to synthesize mono-size PVP-coated iron oxide nanoparticles for biomedical application. ${ }^{18}$ Sun et al reported the synthesis of polyethylene glycol (PEG)-coated iron oxide nanoparticle for specific targeting of glioma tumors via the surface-bound targeting peptide, chlorotoxin. ${ }^{23}$ Nazli et al reported the synthesis of PEG hydrogel-coated iron oxide nanoparticles for enhanced intracellular uptake by HeLa cells. ${ }^{24}$ Jarrett et al and Yu et al synthesized dextran-coated iron oxide nanoparticles controlling the particle sizes. ${ }^{25,26}$ Progress in development of nanoparticle-based therapeutic and diagnostic platforms is expected to offer incredible potential for advanced diagnosis and tumor treatment. Starch, ethyl cellulose, chitosan, and gelatin polysaccharides are also used by several researchers to coat iron oxide nanoparticles for MRI, drug delivery, and different biomedical applications. ${ }^{28-35}$ Saboktakin et al used iron oxide nanoparticles of $10 \mathrm{~nm}$ diameter coated with starch for MRI. ${ }^{28}$ Saikia et al studied the $\mathrm{pH}$-sensitive drug delivery potentiality of starch-coated iron oxide nanoparticles $(8-20 \mathrm{~nm}),{ }^{29}$ whereas $\mathrm{Ma}$ et al and Bekaroğlu et al reported the successful application of hydroxyethyl cellulose-coated iron oxide nanoparticles in targeted drug delivery. ${ }^{30,31}$ Gaihre et al reported gelatincoated doxorubicin-loaded iron oxide nanoparticles and their drug-loading and drug-releasing kinetics with variable pH. ${ }^{32,33}$ In food industry, fatty acid-coated iron oxide nanoparticles are widely used as biocatalyst because of their excellent catalytic activity and easy separation of the catalyst post-reaction by applying an external magnetic field..$^{36,37}$ Kalidasan et al reported enhanced biocompatibility and magnetic hyperthermia performance of bovine serum albumin-coated iron oxide nanoparticles. ${ }^{38}$ For targeted drug delivery, it is very important to improve surface functionality with specific functional groups. Zhang et al enhanced intracellular uptake of iron oxide nanoparticles by successful immobilization of folic acid over their surface. Along with folic acid, they coated PEG over the iron oxide surface and studied the uptake by RAW 264.7 (mouse macrophage) and BT20 (human breast cancer) cell lines..$^{39}$ Gupta et al reported the synthesis of insulin-coated iron oxide nanoparticles where insulin acted as a surface ligand to prevent endocytosis. ${ }^{40}$ Liu and Huang synthesized a novel liposome-coated magnetic hydroxyapatite (MHAp) drug vehicle with ultrasound-triggered MRI contrast-changing property. ${ }^{41}$
The advantages of polymers are that they are easy to fabricate and easy to coat over nanoparticles, and a wide variety of polymers are available with different functional groups. However, some serious disadvantages of polymers restrict $\sim 95 \%$ of experimental results obtained in laboratory from translating to clinical application. The three major problems associated with polymers are as follows: (1) they are usually very unstable (affected by varying $\mathrm{pH}$ and temperature), (2) they have agglomerating and adherence properties (cause toxic and immunogenic effects), and (3) the hydrodynamic flow inside the body system retards their movement (mostly dissolved in body fluids and degraded because of enzyme activity). Using metals as sole coating agents is strongly discouraged owing to their toxic effects, fabrication difficulties, and synthesis-associated costs. The advancement of nanotechnology has led to the development of metallic nanostructure surfaces or materials for biomedical applications. Metals such as gold, silver, zinc, and platinum show good prospects to enhance magnetization and optical and electrochemical properties of materials. ${ }^{42-46}$ Silva et al and Elsherbini et al reported the synthesis and biomedical applications, such as drug delivery, hyperthermia, photothermal therapy, and imaging, of gold-coated iron oxide nanoparticles. ${ }^{42,43}$ Silver is an excellent antibacterial agent. Mahmoudi and Serpooshan reported the synthesis of antimicrobial magnetic silver ring-coated nanoparticles which were targeted to bacterial biofilm by an external magnetic field. ${ }^{44}$ Platinum coating over magnetic nanoparticle is very less reported, but Kwon et al synthesized platinum-coated magnetic nanoparticles for colorimetric detection of pathogenic bacteria and magnetophoretic chromatography application..$^{45}$ Thomas et al developed zinc-doped iron oxide nanocrystals with mesoporous silica framework as drug delivery vehicle for controlled release of drug molecules achieved by external magnetic hyperthermia effect. ${ }^{46}$ For magnetic nanoparticles to be efficiently used in medicine, they should be extremely biocompatible, stable, and securely eliminated from the body system. Researchers are currently paying more attention to bioceramic coatings which have many added advantages over conventional polymeric coatings. Metal oxides such as $\mathrm{TiO}_{2}$ and $\mathrm{SiO}_{2}$ including calcium phosphate coating over nanoparticles are well studied by several researchers. ${ }^{47-49}$ Yang et al synthesized mesoporous and nonmesoporous silica-coated iron oxide nanoparticles for luminescent and drug delivery applications. ${ }^{47}$ Ye et al reported the synthesis of mesoporous silica-coated iron oxide nanoparticles for use as nontoxic MRI contrast agent. ${ }^{48}$ Calcium phosphate is a well-known bioceramic for biomedical application, specifically 
for bone tissue engineering. Pareta et al reported calcium phosphate-coated iron oxide nanoparticles with increasing osteoblast density which could be a promising material for bone tissue engineering application. ${ }^{50}$ Bioactive coating with hydroxyapatite is an important condition to enhance biological functionality which favors the adhesion and proliferation of osteoblasts over implant materials. ${ }^{51}$ Among different bioceramics, HAp is the prime choice for researchers because of its high biocompatibility and osteoconductivity. Kumar et al elucidated the synthesis, mechanical property, biological property, and application of different three-dimensional (3D) HAp scaffolds developed by different techniques such as 3D printing and rapid prototyping. ${ }^{52,53}$ Maganti et al and TheinHan and Misra reported freezing and lyophilization techniques to prepare chitosan-nanohydroxyapatite scaffold for bone tissue engineering application. ${ }^{54-56}$ In spite of various positive aspects as a suitable biomaterial, low mechanical property is a serious disadvantage of HAp. Kumar et al reported electroconductive HAp and titanium disilicide composite system to overcome the fracture toughness from $0.6 \mathrm{MPa} \cdot \mathrm{m}^{1 / 2}$ (HAp) to $1.2 \mathrm{MPa} \cdot \mathrm{m}^{1 / 2}$ (titanium disilicide composite HAp).$^{57}$ The study further extended to explain the increased electrical conductivity of titanium disilicide HAp composite which stimulated myoblast proliferation. ${ }^{57-59}$ Depan et al studied the cellular response with electrical stimulation effect of different electroactive nanostructure composites ${ }^{58}$ Mondal et al reported natural-origin and synthetic hydroxyapatite for different biomedical engineering and scaffold development applications. ${ }^{60-64}$

HAp is a well-recognized nontoxic biocompatible material that has good stability and a flexible structure that allows easy assimilation of magnetic ions. Iron is the most frequently used metal for imparting HAp with magnetic properties. This review addresses recent advances in the use of MHAp and the possibilities and limitations from fabrication to biomedicinal applications. In addition, different synthetic routes and surface modifications of desired MHAp for application in drug delivery, tissue engineering, and scaffold development are carefully discussed (Table 3). ${ }^{65-87}$ The use and effect of an applied magnetic field for drug delivery and release, mechanical cell stimulation, and hyperthermia effects are also discussed. ${ }^{65-87}$

\section{Different synthesis routes of magnetic HAp}

The synthesis of HAp and iron oxide nanoparticles by different routes has already been well discussed by many researchers worldwide. However, the synthesis of MHAp is less researched compared with that of HAp and iron oxide. This review attempts to focus on almost every aspect of synthesis procedures of MHAp, which are opted by researchers, and their application to date. Wu et al reported the synthesis of MHAp nanoparticles using a two-step wet chemical process. Calcium hydroxide $\left[\mathrm{Ca}(\mathrm{OH})_{2}\right]$ was reacted with

Table 3 Different synthetic routes of MHAp and its applications

\begin{tabular}{|c|c|c|c|c|}
\hline S no & Synthesis route & Application & Magnetic saturation (Ms) & References \\
\hline I & Solution intercalation method & Gene therapy and drug delivery & - & 62 \\
\hline 2 & Template-assisted self-assembly & Gene delivery & - & 63 \\
\hline 3 & Wet precipitation & $\begin{array}{l}\text { Biomedicine application, } \\
\text { hyperthermia study }\end{array}$ & $7.23-20.92 \mathrm{emu} / \mathrm{g}$ & 65,69 \\
\hline 4 & Ion exchange procedure & Theoretical calculation & - & 71 \\
\hline 5 & Pulsed plasma deposition & Biofilm formation & $0.26 \mathrm{emu} / \mathrm{g}$ & 73 \\
\hline 6 & Hydrothermal method & Biomedical orthopedic applications & Approximately 0.32 emu/g & 74 \\
\hline 7 & Spray-drying technique & Medical diagnosis and imaging & Approximately 12 emu/g & 75 \\
\hline 8 & Microwave-assisted route & $\mathrm{pH}$-responsive drug release & $18.9 \mathrm{emu} / \mathrm{g}$ & 76 \\
\hline 9 & $\begin{array}{l}\text { Four-step synthesis associated with wet } \\
\text { precipitation, ultrasonication, hydrothermal } \\
\text { method, and layer-by-layer coating }\end{array}$ & $\begin{array}{l}\text { Magnetic resonance imaging, } \\
\text { drug delivery }\end{array}$ & Approximately 4-7 emu/g & 77 \\
\hline 10 & Hydrothermal method & $\begin{array}{l}\mathrm{pH} \text {-dependent protein adsorption } \\
\text { release carrier }\end{array}$ & II.5-I5.5 emu/g & 78 \\
\hline II & Polymer-templated electrospun method & Biomedical and hyperthermia treatment & $27.20 \mathrm{emu} / \mathrm{g}$ & 79 \\
\hline 12 & Mechanochemical method & Hyperthermia treatments & - & 80 \\
\hline 13 & Ultrasonic irradiation technique & Biomedicine application & $7.40 \mathrm{emu} / \mathrm{g}$ & 81 \\
\hline 14 & $\begin{array}{l}\text { Other synthetic routes (electrophoretic } \\
\text { deposition, biogenic source, chemical } \\
\text { precipitation) }\end{array}$ & $\begin{array}{l}\text { Solid-phase extraction of plasmid DNA, } \\
\text { medical imaging }\end{array}$ & - & $\begin{array}{l}65,69 \\
82-95\end{array}$ \\
\hline
\end{tabular}

Abbreviation: MHAp, magnetic hydroxyapatite. 
orthophosphoric acid for $20 \mathrm{~h}$ in an inert (Ar) condition to synthesize HAp nanocrystals. Next, $\mathrm{FeCl}_{2} \cdot 4 \mathrm{H}_{2} \mathrm{O}$ was added and stirred at an ambient environment $\left(80^{\circ} \mathrm{C}\right.$ and $\left.\mathrm{pH} 8.0-8.5\right)$ for $10 \mathrm{~h}$ to obtain a $\mathrm{Ca} / \mathrm{Fe}$ molar ratio of 0.75 . The obtained MHAp was washed several times to achieve a neutral $\mathrm{pH}$ for further gene delivery studies. ${ }^{65}$ Shan et al reported a similar wet precipitation method for synthesizing MHAp for solidphase plasmid DNA (pDNA) extraction. ${ }^{66}$ Zuo et al synthesized laminated MHAp via a solution intercalation method. In their study, $1.0 \mathrm{~g}$ sodium dodecyl sulfonate was dissolved in $15 \mathrm{~mL}$ deionized (DI) water with $30 \mathrm{~mL}$ ethanol, followed by heating at $60^{\circ} \mathrm{C}$. Next, $15 \mathrm{~mL}$ of $3.3 \mathrm{M}$ calcium nitrate and $30 \mathrm{~mL}$ of $1 \mathrm{M}$ diammonium hydrogen phosphate were added to $30 \mathrm{~mL}$ of ethanol. Then, $20 \mathrm{~mL}$ of $2.5 \mathrm{M} \mathrm{NaOH}$ and $20 \mathrm{~mL}$ of ethanol were added to the mixture and stirred for $30 \mathrm{~min}$. To synthesize magnetic nanoparticles, $7.5 \mathrm{~mL}$ of 2.4 M iron (III) chloride, $7.5 \mathrm{~mL}$ of $1.2 \mathrm{M}$ iron (II) chloride, and $30 \mathrm{~mL}$ of $3 \mathrm{M} \mathrm{NaOH}$ were mixed, after which $45 \mathrm{~mL}$ of ethanol was added. The mixture was refluxed for $14 \mathrm{~h}$ at $85^{\circ} \mathrm{C}$ and left at room temperature for 21 days to develop laminated MHAp. ${ }^{67}$ Xiong et al synthesized self-assembled lamellar MHAp for gene delivery application following a similar synthetic method by Zuo et al. ${ }^{68}$ The synthesized MHAp lamellar structure was further loaded with a DNA molecule for gene delivery application. Gopi et al dissolved iron (II) perchlorate and iron (III) perchlorate in DI water (1:2 $\mathrm{M}$ ratio), which resulted in the formation of a pale yellow-colored solution. Next, this solution was ultrasonicated ( $28 \mathrm{kHz}$ at $150 \mathrm{~W})$, and after $5 \mathrm{~min}$, HAp nanoparticles were dispersed in it. A little amount of DI water was added to the gel formed via sonication, and the $\mathrm{pH}$ of the solution adjusted to 8 by adding $1 \mathrm{M}$ sodium hydroxide. A black color precipitate immediately appeared owing to the formation of MNPs. Ultrasonic irradiation was continued for the formation of homogenized MHAp in an inert atmosphere. Hou et al followed the similar pathway of Wu et al for synthesizing MHAp nanoparticles in an in vivo hyperthermia study with the mice model. ${ }^{69}$ Laranjeira et al prepared MHAp nanoparticles doped with different magnetic dopants (Gd, $\mathrm{Co}$, and Fe) by wet precipitation method. First, they used calcium hydroxide as the calcium precursor and then added gadolinium chloride hexahydrate, cobalt nitrate hexahydrate, iron nitrate nonahydrate, and iron chloride tetrahydrate $(2.5 \%-10 \%)$ to phosphoric acid at $\mathrm{pH} 7.4$ with stirring for $2 \mathrm{~h}$ and overnight aging. They performed separate reactions for separate doping and reported that $10 \%$ of Gd and Fe (III) offered maximum magnetic saturation, although the exact value was not mentioned. The study also assessed cytotoxic, hemocompatibility, hemolytic, and thrombogenic effects of various MHAp, of which Gd-doped MHAp was the most biocompatible. ${ }^{70}$ Zilm et al reported the wet chemical synthesis of HAp using calcium nitrate $(225 \mathrm{mM})$ and diammonium hydrogen phosphate $(80 \mathrm{mM})$ in a basic ( $\mathrm{pH} 11)$ condition. The synthesized HAp was further used for an ion exchange procedure to synthesize MHAp. The study reported that different salts $\left(\mathrm{FeCl}_{2}, \mathrm{CoCl}_{2}\right.$, and $\left.\mathrm{MnCl}_{2}\right)$ with a concentration of $0.02 \mathrm{M}$ were used for synthesizing different MHAp. The synthesized HAp was mixed with different salt solutions and sonicated at room temperature for $1 \mathrm{~h}$. Then, the synthesized MHAp was washed and collected for further use. ${ }^{71}$ Iannotti et al synthesized iron-doped MHAp by the chemical precipitation method. In a calcium hydroxide suspension (20.40 $\mathrm{g}$ in $400 \mathrm{~mL} \mathrm{H} \mathrm{H}_{2} \mathrm{O}$ ), iron (II) (6.03 $\mathrm{g}$ in $75 \mathrm{~mL} \mathrm{H}_{2} \mathrm{O}$ ) and iron (III) chloride ( $8.28 \mathrm{~g}$ in $75 \mathrm{~mL} \mathrm{H}_{2} \mathrm{O}$ ) solutions were simultaneously added. Phosphoric acid solution (20.75 $\mathrm{g}$ in $300 \mathrm{~mL} \mathrm{H}_{2} \mathrm{O}$ ) was added very slowly to the mixture. Next, the solution was heated at $45^{\circ} \mathrm{C}$ for $3 \mathrm{~h}$ and finally left for $24 \mathrm{~h}$ at room temperature for aging. The synthesized MHAp samples were washed and used for further experiments. ${ }^{72}$ Gambardella et al fabricated a magnetite-augmented MHAp film via the pulsed plasma deposition method, in which the biofilm formed was used to study bacterial adhesion. A mixture of HAp and magnetite (90:10 wt.\%) was ball milled with 1.5 wt.\% Dolapix CE-64 (dispersant) and finally sintered at $1,200^{\circ} \mathrm{C}$ for $1 \mathrm{~h}$. This sintered material was further used with PPD system to make a film layer. ${ }^{73}$ Tran and Webster synthesized MHAp nanoparticles by dissolving $\mathrm{FeCl}_{2} \cdot 4 \mathrm{H}_{2} \mathrm{O}$ and $\mathrm{FeCl}_{3} \cdot 6 \mathrm{H}_{2} \mathrm{O}$ (1:2 molar ratio) in DI water in the presence of $\mathrm{HCl}$. The solution was then added dropwise to an ammonium hydroxide solution ( $\mathrm{N}_{2}$ atmosphere with vigorous stirring), resulting in the formation of black MNPs, and citric acid was mixed as a surfactant with the mixture. After washing and separation, the MNPs were added to $1 \mathrm{M} \mathrm{CaNO}_{3} \cdot 4 \mathrm{H}_{2} \mathrm{O}$ solution. This mixture was added dropwise to $0.6 \mathrm{M}$ potassium phosphate while stirring, and finally, the precipitated materials were hydrothermally treated for $20 \mathrm{~h}$ at $200^{\circ} \mathrm{C}$. Finally, the obtained MHAp was used for an increased osteoblast study. ${ }^{74}$ Researchers employed a co-precipitation method with chloride salts to synthesize iron MNPs. Instantly, HAp nanoparticles were synthesized by using $\mathrm{CaHPO}_{4} \cdot 2 \mathrm{H}_{2} \mathrm{O}$ and $\mathrm{CaCO}_{3}$ through mechanochemical wet milling. MNPs were integrated into the HAp matrix during the milling process. The researchers only reported the saturation magnetization of synthesized iron oxide nanoparticles, which was $47 \mathrm{emu} / \mathrm{g}$. However, after coating with HAp, no magnetic saturation was reported. Donadel et al reported a HAp coating of iron oxide magnetic particles by spray-drying. MNPs were synthesized by the alkaline co-precipitation of ferric 
$(0.25 \mathrm{~mol} / \mathrm{L})$ and ferrous $(0.125 \mathrm{~mol} / \mathrm{L})$ solutions in the presence of $\mathrm{NaOH}$ solution $(1 \mathrm{~mol} / \mathrm{L})$ at a high $\mathrm{pH}$ with vigorous stirring. MHAp nanoparticles were synthesized by adding diammonium hydrogen phosphate and calcium nitrate into the solution containing iron oxide nanoparticles (previously synthesized). The synthesized MHAp nanoparticles were spray-dried and atomized using the Büchi B-191 dryer with an inlet temperature of 170 and $90^{\circ} \mathrm{C}$ and a pressure of 5 bar gauge. ${ }^{75}$

$\mathrm{Xu}$ et al reported the use of MHAp nanoworms for diagnosing acute hepatic injury by MRI. They briefly discussed four steps for synthesizing MHAp nanoworms. In step 1, HAp nanowillows were prepared using $0.303 \mathrm{~g}$ urea in $20 \mathrm{~mL}$ ethanol-water (3:1), after which $\mathrm{CaCl}_{2}$ and $\mathrm{NaH}_{2} \mathrm{PO}_{4}$ were added under a heating condition of $80^{\circ} \mathrm{C}(\mathrm{pH} 11.9)$ for $24 \mathrm{~h}$. In step 2, after washing, the obtained HAp nanowillows, $\sim 30 \mathrm{mg}$, were suspended and ultrasonicated in DI water. Next, poly(sodium-p-styrenesulfonate) (PSS) was dissolved in $0.04 \mathrm{M} \mathrm{NaCl}$ solution. From this, $0.6 \mathrm{~mL}$ PSS-NaCl solution and $0.3 \mathrm{~mL} \mathrm{NaCl}$ were added with vortexing for $2 \mathrm{~min}$.
After $30 \mathrm{~min}$, the samples were washed and freeze-dried for use in step 3. In step 3, HAp and iron oxide nanocomposites were prepared by dispersing HAp-PSS in $30 \mathrm{~mL}$ triethylene glycol and ultrasonicating the mixture, after which 30/60/90 mg iron (III) 2,4-pentanedionate was added. The solution was heated at $135^{\circ} \mathrm{C}$ for $30 \mathrm{~min}$ while vigorously stirring. Finally, the solution was autoclaved at $220^{\circ} \mathrm{C}$ for $4 \mathrm{~h}$ and washed. In step 4, the obtained MHAp nanoworms were redispersed in $3 \mathrm{~mL}$ DI water with ultrasonication, and $3 \mathrm{~mL}$ chitosan was added for 2 min. After washing, the obtained MHAp chitosan nanoworms were dispersed in a sodium alginate solution. The chitosan and sodium alginate coating steps were repeatedly performed four times for layer-by-layer coating of MHAp nanoworms. ${ }^{76}$

Bharath et al prepared MHAp via the hydrothermal route using iron (II) and (III) chloride salts as magnetite precursors and calcium chloride dihydrate and diammonium hydrogen phosphate as HAp precursors (Figure 1A and C). First, $0.01 \mathrm{M}$ diammonium hydrogen phosphate and $0.1 \mathrm{M}$ $N$-cetyl- $N, N, N$-trimethyl ammonium bromide (CTAB) were
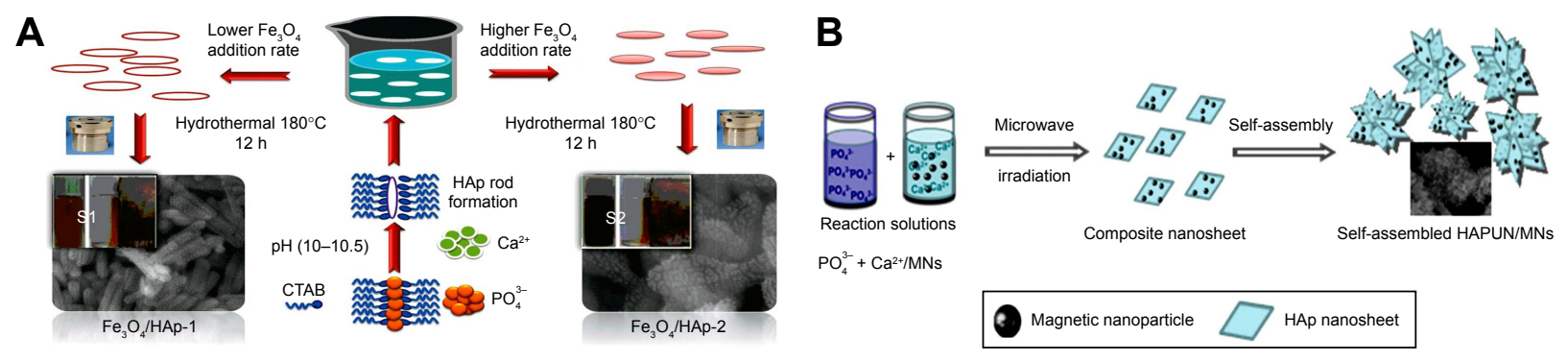

$\mathrm{PO}_{4}^{3-}+\mathrm{Ca}^{2+} / \mathrm{MNs}$
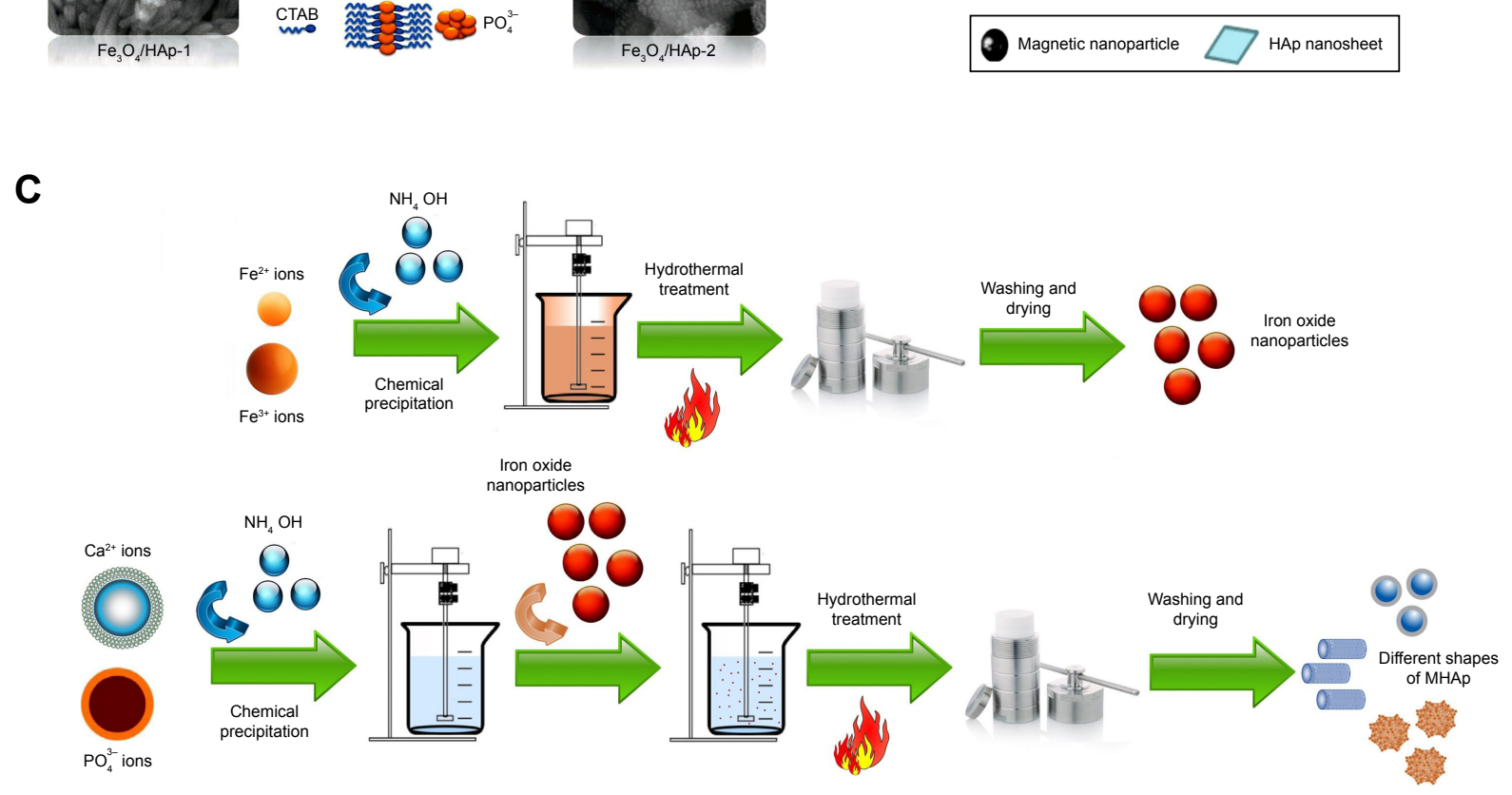

Figure I Different synthesis routes of MHAp nanostructures. Schematic illustration of (A) formation mechanism of one-dimensional MHAp nanorods, (B) synthesis of ultrathin MHAp nanosheet (HAPUN/MNs), and (C) chemical precipitation and hydrothermal synthesis of MHAp. (A) Reproduced from Bharath G, Prabhu D, Mangalaraj $\mathrm{D}$, Viswanathan $\mathrm{C}$, Ponpandian $\mathrm{N}$. Facile in situ growth of $\mathrm{Fe}_{3} \mathrm{O}_{4}$ nanoparticles on hydroxyapatite nanorods for $\mathrm{pH}$ dependent adsorption and controlled release of proteins. RSC Adv. 2014;4(92):50510-50520 with permission of The Royal Society of Chemistry." (B) Reproduced from Chen F, Li C, Zhu YJ, Zhao XY, Lu BQ, Wu J. Magnetic nanocomposite of hydroxyapatite ultrathin nanosheets/ $\mathrm{Fe}_{3} \mathrm{O}_{4}$ nanoparticles: microwave-assisted rapid synthesis and application in $\mathrm{pH}$-responsive drug release. Biomater $\mathrm{Sci}$. 2013; I (10): 1074-108I with permission of The Royal Society of Chemistry. ${ }^{78}$

Abbreviations: MHAp, magnetic hydroxyapatite; HAp, hydroxyapatite; CTAB, N-cetyl-N,N,N-trimethyl ammonium bromide. 
mixed in $10 \mathrm{~mL}$ DI water. Simultaneously, $0.03 \mathrm{M}$ of calcium chloride dihydrate was prepared by dissolving in $10 \mathrm{~mL}$ DI water, and previously prepared CTAB phosphate solution was added to this solution with vigorous stirring at $\mathrm{pH} 10.5$. To this solution, $0.01 \mathrm{M}$ iron (II) and $0.015 \mathrm{M}$ iron (III) chloride solutions were added with basic $\mathrm{pH}$ 10.5. Similarly, different concentrations of other iron chloride salts were used to prepare two different concentrations of iron oxide-loaded HAp (MHAp:MHAp $=0.5: 1 \mathrm{M}$ ). After vigorous stirring, the solution was autoclaved at $180^{\circ} \mathrm{C}$ for $12 \mathrm{~h}$. Two different concentrations of ( 0.5 and $1 \mathrm{M}, \mathrm{Fe}: \mathrm{HAp}$ ) MHAp were prepared. The final MHAp particles were washed and used for further experimental study of a $\mathrm{pH}$ protein delivery carrier. ${ }^{77}$

Chen et al prepared HAp ultrathin nanosheets (HAPUN/ MNs) comprising $\mathrm{Fe}_{3} \mathrm{O}_{4}$ magnetic nanoparticles by rapid microwave method (Figure 1B). In a solvent system of $15 \mathrm{~mL}$ DI water and $15 \mathrm{~mL}$ ethylene glycol, $1 \mathrm{mmol} \mathrm{Ca}\left(\mathrm{CH}_{3} \mathrm{COO}\right)_{2}$, $0.10 \mathrm{~g}$ poly(L-lactic acid)-methoxy PEG, and $0.05 \mathrm{~g} \mathrm{Fe}_{3} \mathrm{O}_{4}$ nanoparticles were dissolved. Next, $10 \mathrm{~mL}$ of $1 \mathrm{mmol}$ $\mathrm{NaH}_{2} \mathrm{PO}_{4} \cdot 2 \mathrm{H}_{2} \mathrm{O}$ solution was added dropwise to the previous mixture. Finally, the mixture was poured into a Teflon-lined steel chamber and microwave heated to $120^{\circ} \mathrm{C}$ for $30 \mathrm{~min}$. The synthesized material was washed and separated using a magnet for a further drug delivery study. ${ }^{78}$

Singh et al reported the synthesis of MHAp nanotubes by poly(caprolactone) template electrospun method. The experimental study was performed by preparing a $10 \%$ (w/v) suspension of poly(caprolactone) in MNPs (20 wt.\%) containing dichloromethane-ethanol solvent. This mixture was then electrospun (field strength, $15 \mathrm{kV} / 10 \mathrm{~cm}$ ) into a nanofiber mesh, and the obtained nanofibers were activated in $2 \mathrm{M} \mathrm{NaOH}$ solution for $4 \mathrm{~h}$. Next, the nanofibers were alternatively soaked in $150 \mathrm{mM} \mathrm{CaCl} 2$ and $\mathrm{Na}_{2} \mathrm{HPO}_{4}$ solutions followed by apatite mineralization by dipping in a 1.5 times-simulated body fluid solution for a week at $37^{\circ} \mathrm{C}$. The obtained MHAp nanofibers were finally calcined at $500^{\circ} \mathrm{C}$ for $5 \mathrm{~h}$ to obtain hollow MHAp nanofibers. ${ }^{79}$

Different methods of synthesizing MHAp produce different types of nanostructures. Researchers have also been tailoring MHAp nanostructures according to their nature of applications (Figure 2). The very interesting part of such MHAp nanoparticles is their equally important multifunctional property suitable for many different applications such as environmental and biomedical applications, adsorption, and catalysis.

Synthesized MHAp nanomaterials are characterized by several sophisticated analytical methods such as X-ray diffraction, scanning and transmission electron microscopy, thermogravimetric and differential thermal analysis, energy-dispersive X-ray spectroscopy, Fourier transformed infrared spectroscopy, and vibrating sample magnetometer analysis to determine their phase purity, morphology, thermal stability, qualitative chemical composition, functional groups, and magnetic saturation, respectively.

\section{Biomedical scaffold}

The main objective of tissue engineering is the development of novel orthopedic strategies based on a multidisciplinary approach for the augmentation, restoration, and regeneration of damaged or diseased tissues. ${ }^{91}$ MHAp scaffolds have been proposed as an advanced tissue engineering tool to increase bone regeneration by providing a fixed platform for controlled accumulation, delivery, and release of essential growth factors, stem cells, or other bioactive molecules directly to the implantation site. Many researchers have already demonstrated the external biophysical stimulations (ultrasound, magnetic pulse, electrical stimulation, etc.) which may act as an important factor for new bone cell regeneration. ${ }^{92}$ Study reports suggest that compared to conventional scaffold materials, MHAp scaffolds have more potential to control the cell growth and scaffold architecture after implantation by external magnetic field stimulation for bone tissue engineering. ${ }^{92-95}$ MHAp nanoparticles at nanoscale level act as a single magnetic domain to facilitate micromotion at the interface between cells and scaffold, which might trigger the ion channels on the cell membrane, and activate the mechanotransduction pathway, leading to increase in cell growth, proliferation, and differentiation. ${ }^{96}$

Panseri et al demonstrated a novel method for facilitating the fixation of MHAp collagen-based scaffolds by reducing micromotion at the scaffold-tissue interface. The scaffold architecture orientation based on magnetic forces is clearly described in their study. By employing two approaches, two types of scaffolds were fabricated with a diameter and height of $4 \mathrm{~mm}$ each. In the first method, biomagnetic apatite, that is, 7 wt.\% magnetic nanoparticles with collagen fibrils, was used as the magnetic scaffold A (MAG-A). The second-type HAp collagen porous scaffold immersed in magnetic ferrofluid was used as the magnetic scaffold B (MAG-B). The in vivo experimental study was performed in 12 healthy male rabbits by inducing surgical defects $(2.0 \mathrm{~mm}$ diameter and $12.0 \mathrm{~mm}$ depth) and positioning the scaffold in the trauma region. The authors explained how magnetic scaffolds implanted in an in vivo system could enhance controlled bone tissue regeneration in a 3D pattern according to the applied very low static magnetic field of $1.2 \mathrm{~T}$ (Figure $3 \mathrm{~A}$ and $\mathrm{B}[\mathrm{a}]$ ). Moreover, the authors hypothesized the fixation of a scaffold using a small pin made of permanent magnets to avoid 

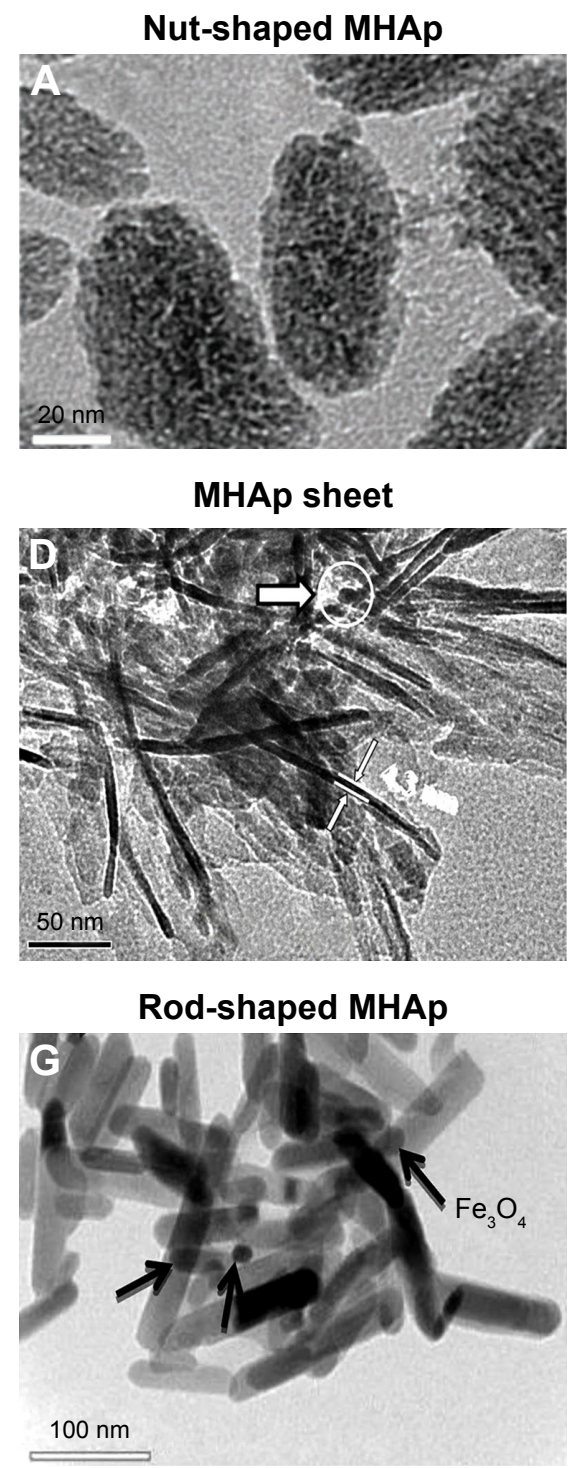

MHAp microsphere

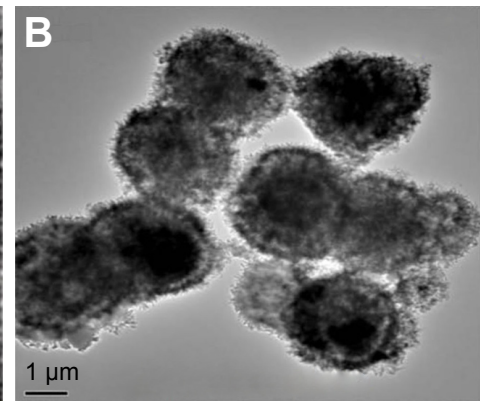

MHAp hollow spherical

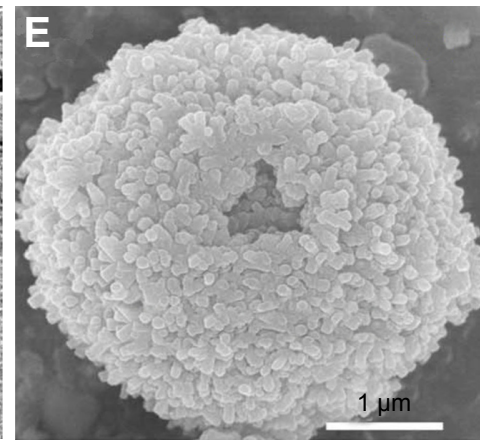

Rice-shaped MHAp

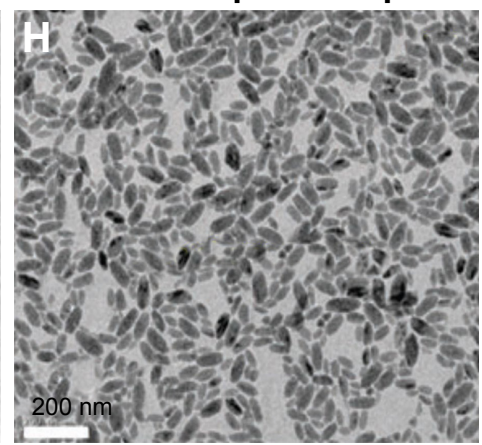

MHAp polygonal

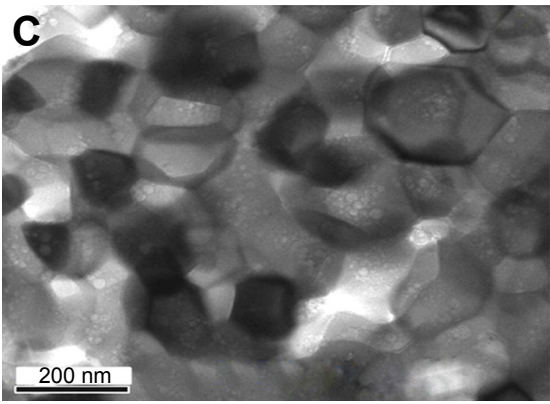

MHAp nanotube

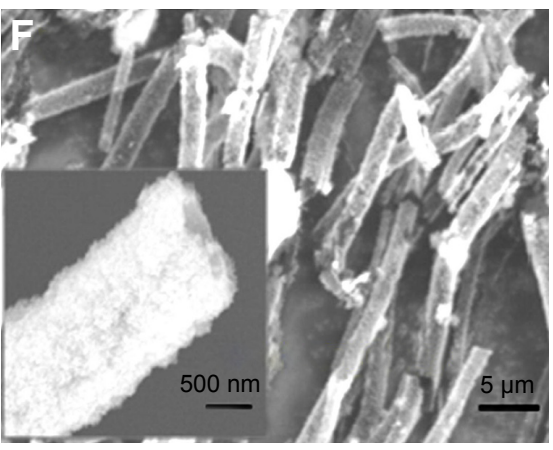

Assembled MHAp

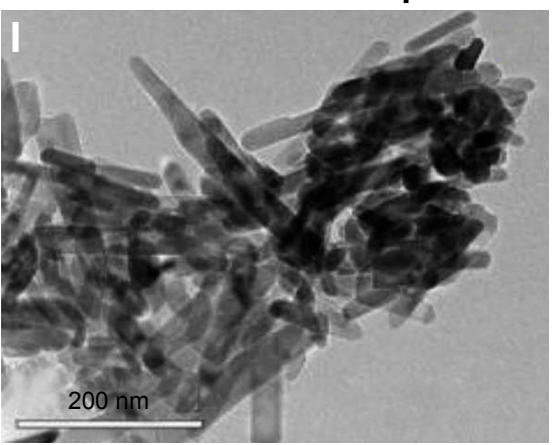

Figure 2 MHAp structure synthesized in different shapes $(\mathbf{A}-\mathbf{H})$. (A) Reproduced from Cui X, Green $\mathrm{MA}$, Blower $\mathrm{PJ}$, et al. $\mathrm{Al}(\mathrm{OH})_{3}$ facilitated synthesis of watersoluble, magnetic, radiolabelled and fluorescent hydroxyapatite nanoparticles. Chem Commun (Camb). 20I5;5I(45):9332-9335 with permission of The Royal Society of Chemistry. ${ }^{88}$ (B) Reproduced from Lin K, Chen L, Liu P, et al. Hollow magnetic hydroxyapatite microspheres with hierarchically mesoporous microstructure for pHresponsive drug delivery. CrystEngComm. 2013;15(15):2999-3008 with permission of The Royal Society of Chemistry. ${ }^{89}$ (C) Reprinted with permission from Boda SK, Anupama AV, Basu B, Sahoo B. Structural and magnetic phase transformations of hydroxyapatite magnetite composites under inert and ambient sintering atmospheres. J Phys Chem C. 2015;119(2):6539-6555. Copyright 2015 American Chemical Society. ${ }^{90}$ (D) Reproduced from Chen F, Li C, Zhu YJ, Zhao XY, Lu BQ, Wu J. Magnetic nanocomposite of hydroxyapatite ultrathin nanosheets/Fe $\mathrm{O}_{4}$ nanoparticles: microwave-assisted rapid synthesis and application in pH-responsive drug release. Biomater Sci. 2013; I (I0): I074-108I with permission of The Royal Society of Chemistry. ${ }^{78}$ (E) Reproduced from Lin K, Chen L, Liu P, et al. Hollow magnetic hydroxyapatite microspheres with hierarchically mesoporous microstructure for $\mathrm{pH}$-responsive drug delivery. CrystEngComm. 20 I3; I5(I5):2999-3008 with permission of The Royal Society of Chemistry. ${ }^{89}$ (F) Reprinted from Singh RK, El-Fiqi AM, Patel KD, Kim HW. A novel preparation of magnetic hydroxyapatite nanotubes. Mater Lett. 20I2;75:I30-I33. Copyright 20I2, with permission from Elsevier. ${ }^{79}$ (G) Reproduced from Bharath G, Prabhu D, Mangalaraj D, Viswanathan C, Ponpandian N. Facile in situ growth of Fe $\mathrm{O}_{4}$ nanoparticles on hydroxyapatite nanorods for $\mathrm{pH}$ dependent adsorption and controlled release of proteins. RSC Adv. 2014;4(92):505I0-50520 with permission of The Royal Society of Chemistry. ${ }^{77}(\mathbf{H})$ Reproduced from Cui X, Green MA, Blower PJ, et al. Al(OH) ${ }_{3}$ facilitated synthesis of water-soluble, magnetic, radiolabelled and fluorescent hydroxyapatite nanoparticles. Chem Commun (Camb). 2015;5I (45):9332-9335 with permission of The Royal Society of Chemistry. ${ }^{88}$ (I) Reproduced from Bharath G, Prabhu D, Mangalaraj $\mathrm{D}$, Viswanathan $\mathrm{C}$, Ponpandian N. Facile in situ growth of $\mathrm{Fe}_{3} \mathrm{O}_{4}$ nanoparticles on hydroxyapatite nanorods for pH dependent adsorption and controlled release of proteins. RSC Adv. 2014;4(92):50510-50520 with permission of The Royal Society of Chemistry. ${ }^{77}$

Abbreviation: MHAp, magnetic hydroxyapatite.

scaffold micromotion and to facilitate enhanced tissue regeneration (Figure $3 \mathrm{~B}[\mathrm{~b}])^{.92}$

Bock et al successfully transformed standard commercial scaffolds (collagen and HAp) to magnetic scaffolds by dipcoating in iron-containing aqueous ferrofluids (Figure 4). The nanoparticles were incorporated into the scaffold structure, facilitating a magnetization value of $15 \mathrm{emu} / \mathrm{g}$ at $10 \mathrm{kOe}$. This developed magnetic scaffold did not have any structural damage and maintained its specific porosity and shape. Moreover, the magnetic scaffold did not release magnetic particles under a constant flow of simulated body fluids over a period of 8 days. The authors also observed a 
A
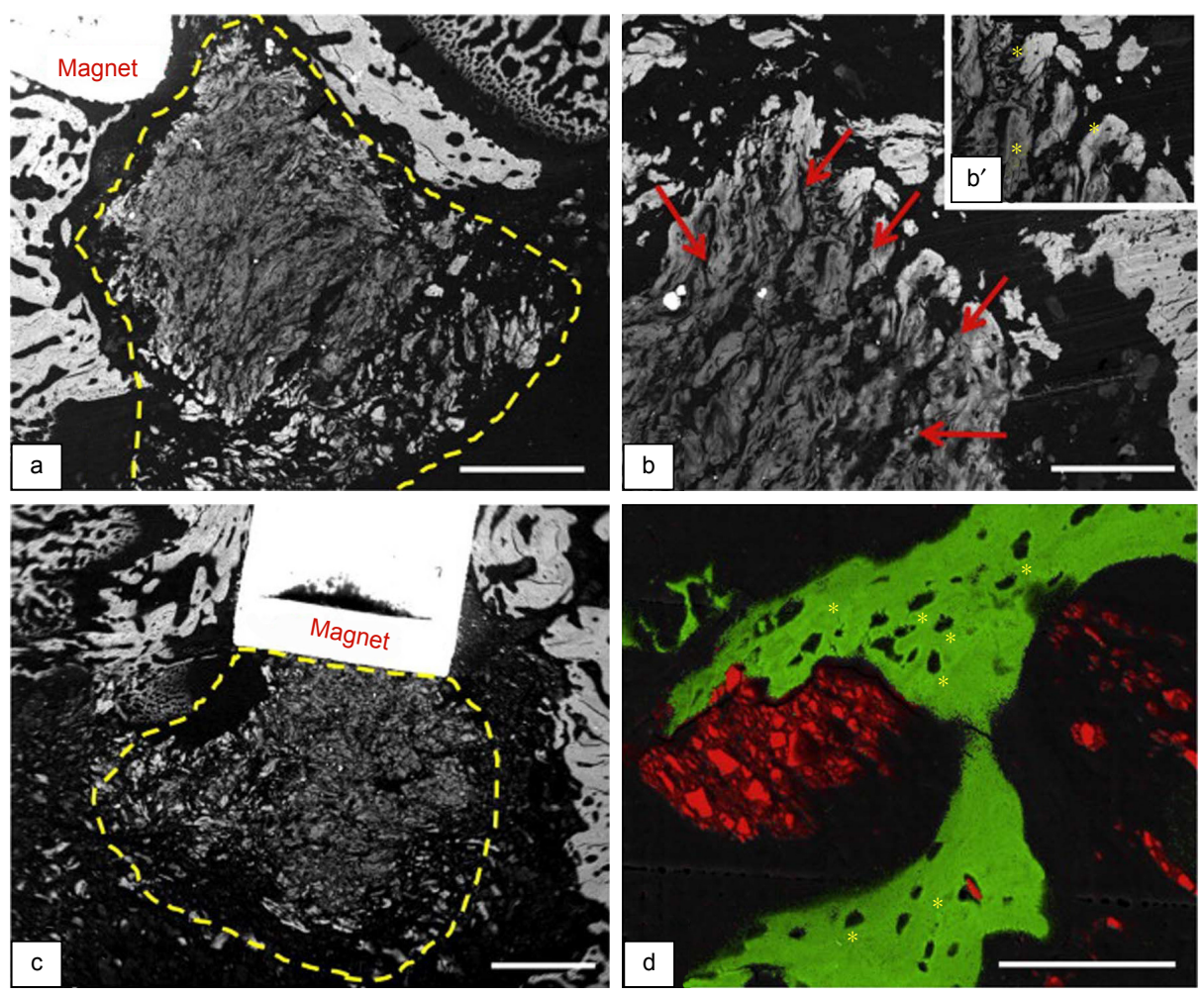

B

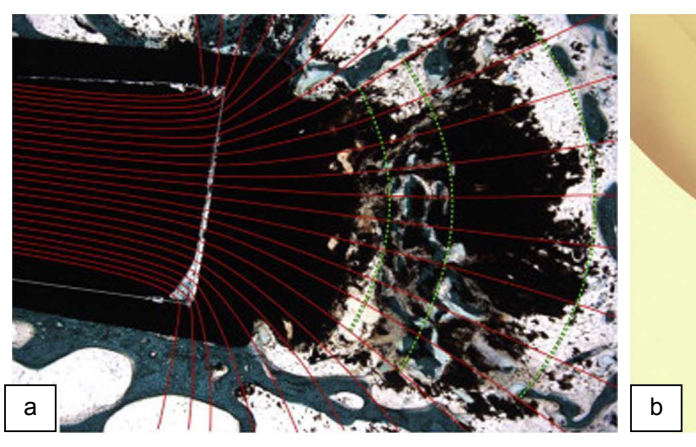

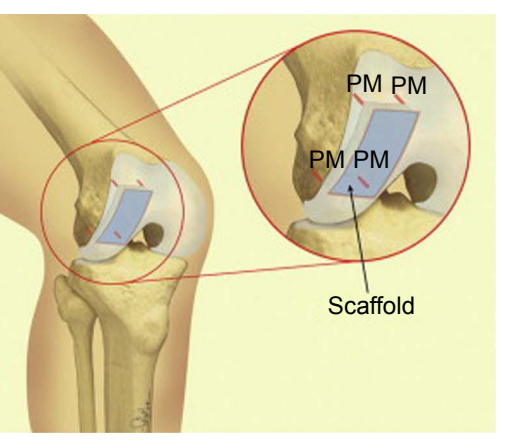

Figure 3 (A) SEM images of new bone tissue growing inside and around magnetic scaffolds: (a) MAG-A; (b) a detail of MAG-A; and (c) MAG-B at 4 weeks. Scaffold delimited by yellow dashed line; red arrows show mineralization. ( $b^{\prime}$ and $d$ ) Osteocyte lacunae (indicated by asterisks) in the new bone grown inside MAG-A and MAG-B, respectively. Scale bars: (a and c) $1.0 \mathrm{~mm}$; (b) $300 \mu \mathrm{m}$; and (d) $100 \mu \mathrm{m}$. Reprinted from Panseri S, Russo A, Sartori M, et al. Modifying bone scaffold architecture in vivo with permanent magnets to facilitate fixation of magnetic scaffolds. Bone. 2013;56(2):432-439. Copyright 2013, with permission from Elsevier.92 (B) Merged images in (a) show magnetic field lines coming out from permanent magnet and resulting scaffold orientation. (b) Schematic presentation of magnet-scaffold fixation with four implanted permanent magnet pins (PM) that hold an osteochondral scaffold. Reprinted from Panseri S, Russo A, Sartori M, et al. Modifying bone scaffold architecture in vivo with permanent magnets to facilitate fixation of magnetic scaffolds. Bone. 2013;56(2):432-439. Copyright 2013, with permission from Elsevier. ${ }^{92}$

Abbreviations: MAG-A, magnetic scaffold A; SEM, scanning electron microscopy.

good biological activity of the magnetic scaffolds supporting adhesion and proliferation of human bone marrow stem cells in vitro. ${ }^{97}$

A similar research was also reported by Tampieri et al, where they developed magnetic biohybrid porous scaffolds. The main constituents of the developed scaffolds were type I collagen (equine tendon extraction) as an organic matrix and HAp; in contrast, the MHAp collagen scaffold was prepared by adding MHAp (synthesized by the chemical precipitation method) to a collagen matrix and was cross-linked with 1,4butanediol diglycidyl ether and cast in a fabricated mold, after which it was freeze-dried at $-25^{\circ} \mathrm{C}$, under vacuum conditions. Although the reported magnetic saturation of the developed composite material was very low $(0.07 \mathrm{emu} / \mathrm{g})$, the bulk approach of developing MHAp collagen scaffolds remains very promising for the future study. ${ }^{98}$

Scaffold fixation is one of the most important challenges in osteogenic corrective surgery. The fixation should be done efficiently to hold the scaffold in a fixed position and for the bone-scaffold interface to facilitate enhanced tissue regeneration. For small-defect repair, fixation is not a major problem, but for large defects $\left(>2 \mathrm{~cm}^{2}\right)$, fixation is a big 


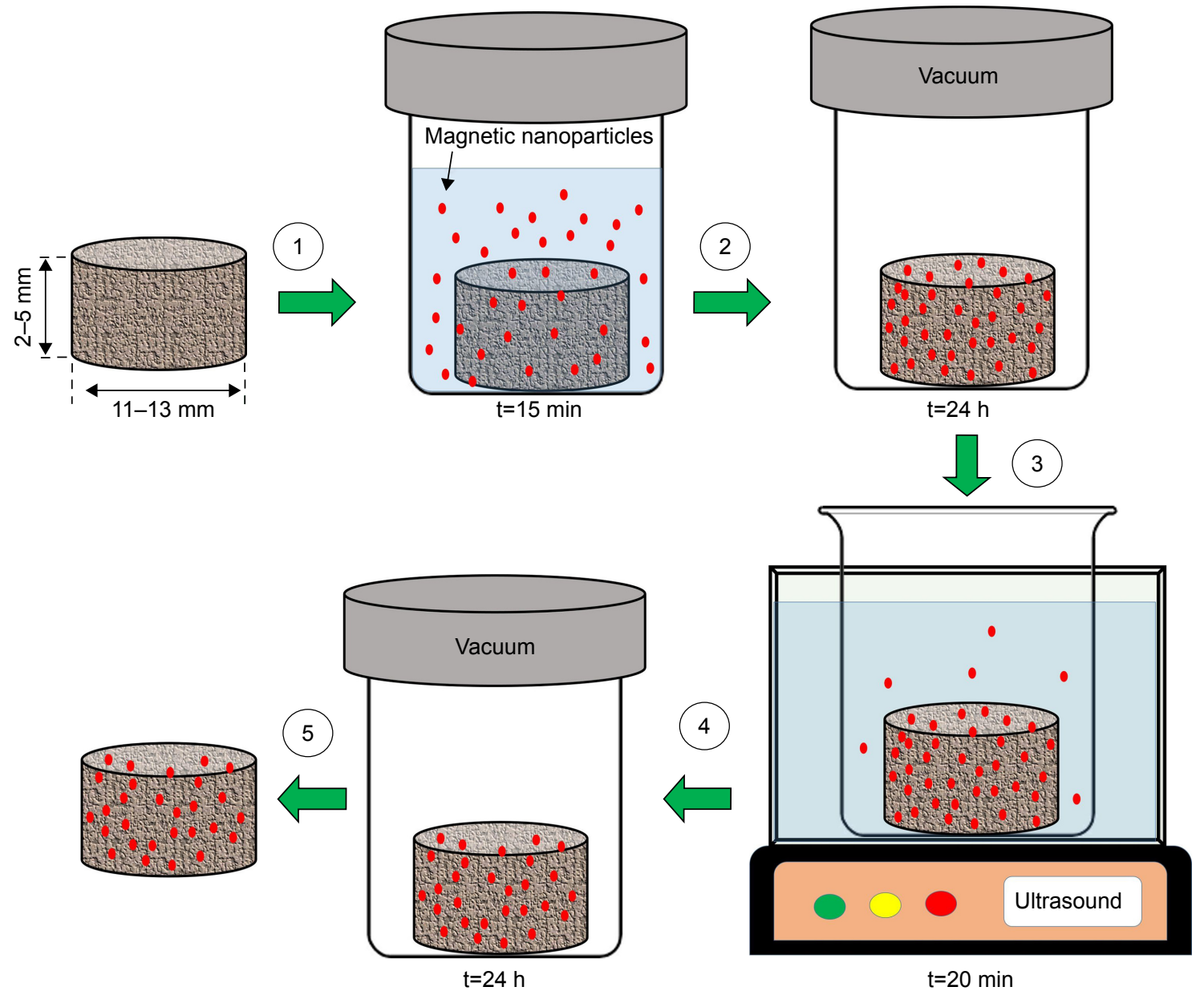

Figure 4 Schematic presentation of scaffolds magnetization process: (I) scaffold is immersed in I mL of ferrofluid for I5 min; (2) scaffold is freeze-dried for 24 h; (3) scaffold is rinsed with deionized water under ultrasonication for $20 \mathrm{~min}$; (4) scaffold is freeze-dried for $24 \mathrm{~h}$; and (5) magnetized scaffold is obtained.

challenge. Russo et al described an innovative magnetic fixation approach based on the application of MHAp scaffold. Mathematical finite element modeling was employed to explore the fixation effectiveness. Three magnetic configurations were utilized as follows: (1) near the joint defect, an external permanent magnet ring was placed around the leg; (2) four small permanent magnet pins were used to fix the bone and scaffold; and (3) similar four stainless steel pins were implanted with an induced external magnetic field (Figure 5). In this study, the scaffolds comprised HAp and collagen immersed and impregnated with biocompatible magnetite ferrofluid. The scaffold size was $3 \times 3 \times 1 \mathrm{~cm}$, with a magnetic saturation of $17 \mathrm{emu} / \mathrm{g}$. Based on the designed experimental study, the most appropriate magnetic materials and optimized magnet-scaffold positioning via a magnetic force facilitated sufficient scaffold fixation for treating osteochondral defects. ${ }^{99}$ Another study from Russo et al reported the enhanced osteoconductive property of MHAp scaffold compared to HAp scaffold studied in vivo in rabbit model after 4 weeks of surgery. The HAp and MHAp scaffolds were able to induce bone tissue development without any adverse effects. The histological analysis of 4-week-implanted HAp and MHAp scaffold showed embedded newly developed bone tissues on scaffold surface (Figure 5A-D). In 12-week implantation study, both types of scaffold surfaces were covered with new bone tissues connected directly with the scaffold materials without any inflammation (Figure 5E-H). The interesting result of this study shows the better mechanical property of MHAp scaffold obtained which is an important criterion for tissue engineering application. ${ }^{100}$

Tran and Webster reported an interesting study on MHAp nanoparticles and their enhanced osteoblast activity. This study showed the synthesis of HAp-coated iron oxide nanoparticles by the wet precipitation method, followed by the hydrothermal method with an average particle size of $170 \mathrm{~nm}$. The magnetic saturation of synthesized MHAp nanoparticles was very less $(\sim 0.32 \mathrm{emu} / \mathrm{g})$. In a biological study 

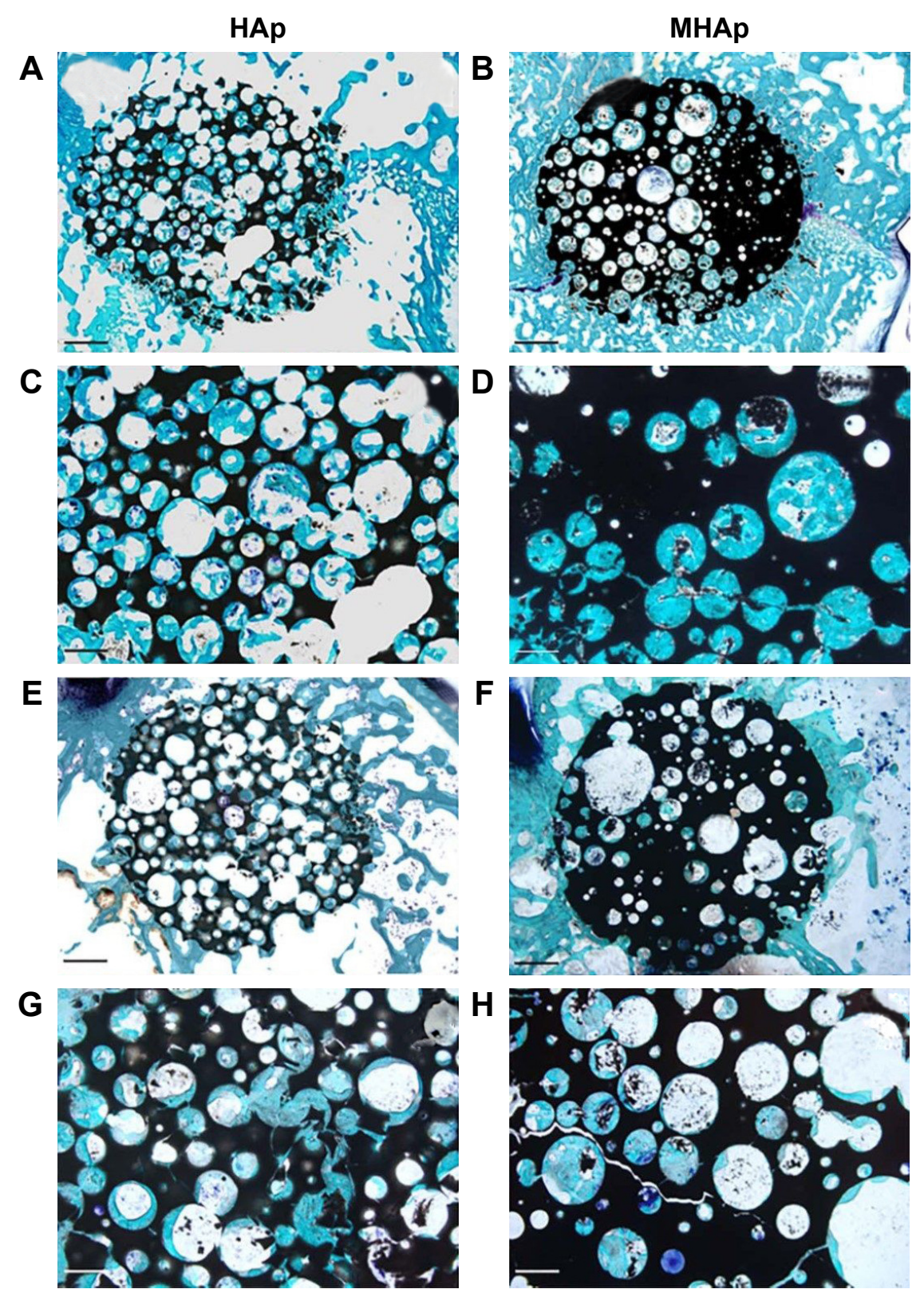

Figure 5 Representative histological views of (A, C, E, and $\mathbf{G})$ HAp and (B, D, F, and $\mathbf{H})$ MHAp scaffolds stained with toluidine blue, acid fuchsin, and fast green at (A-D) 4 and (E-H) 12 weeks from implantation. The low magnification reported in images $(\mathbf{A}, \mathbf{B}, \mathbf{E}$, and $\mathbf{F})$ allows the displaying of the entire scaffold (dark) and of the implant site. Scale bar is I mm in (A, B, E, and F) and $500 \mathrm{~mm}$ in (C, D, G, and H). Reproduced from Russo A, Bianchi M, Sartori M, et al. Bone regeneration in a rabbit critical femoral defect by means of magnetic hydroxyapatite macroporous scaffolds. J Biomed Mater Res B Appl Biomater. Epub 2017 Feb 15. Copyright 2017 Wiley. ${ }^{100}$

Abbreviations: HAp, hydroxyapatite; MHAp, magnetic hydroxyapatite.

with human osteoblasts (ATCC, CRL-11372), synthesized MHAp nanoparticles showed improved collagen synthesis, calcium deposition, and good alkaline phosphatase activity, which are clear indications of enhanced osteoblast activity for treating bone-related disorders. ${ }^{74}$

Zhu et al investigated the in vitro and in vivo development of protein coronas on HAp and MHAp scaffolds and their controlling effects on cell proliferation (Figure 6). HAp disks (14 $\mathrm{mm}$ diameter and $2 \mathrm{~mm}$ height) were immersed in 10.0 wt.\% MNPs colloidal solution for $24 \mathrm{~h}$ and vacuum-dried to form MHAp scaffolds. The saturation magnetization of developed MHAp scaffolds was $\sim 2 \mathrm{emu} / \mathrm{g}$. In this study, MC3T3-E1 cells were used to study the formation of protein corona and its regulatory effect on cell proliferation. This study revealed the significant increase in proteins that regulated cell proliferation. More significantly, the MAPK/ERK signaling pathway, along with two more signaling pathways MEK1/2 and ERK1/2, was triggered in the presence of HAp and MHAp scaffolds. Through a critical investigation of the expression of different proteins, the molecular mechanism 


\section{Cell proliferation}

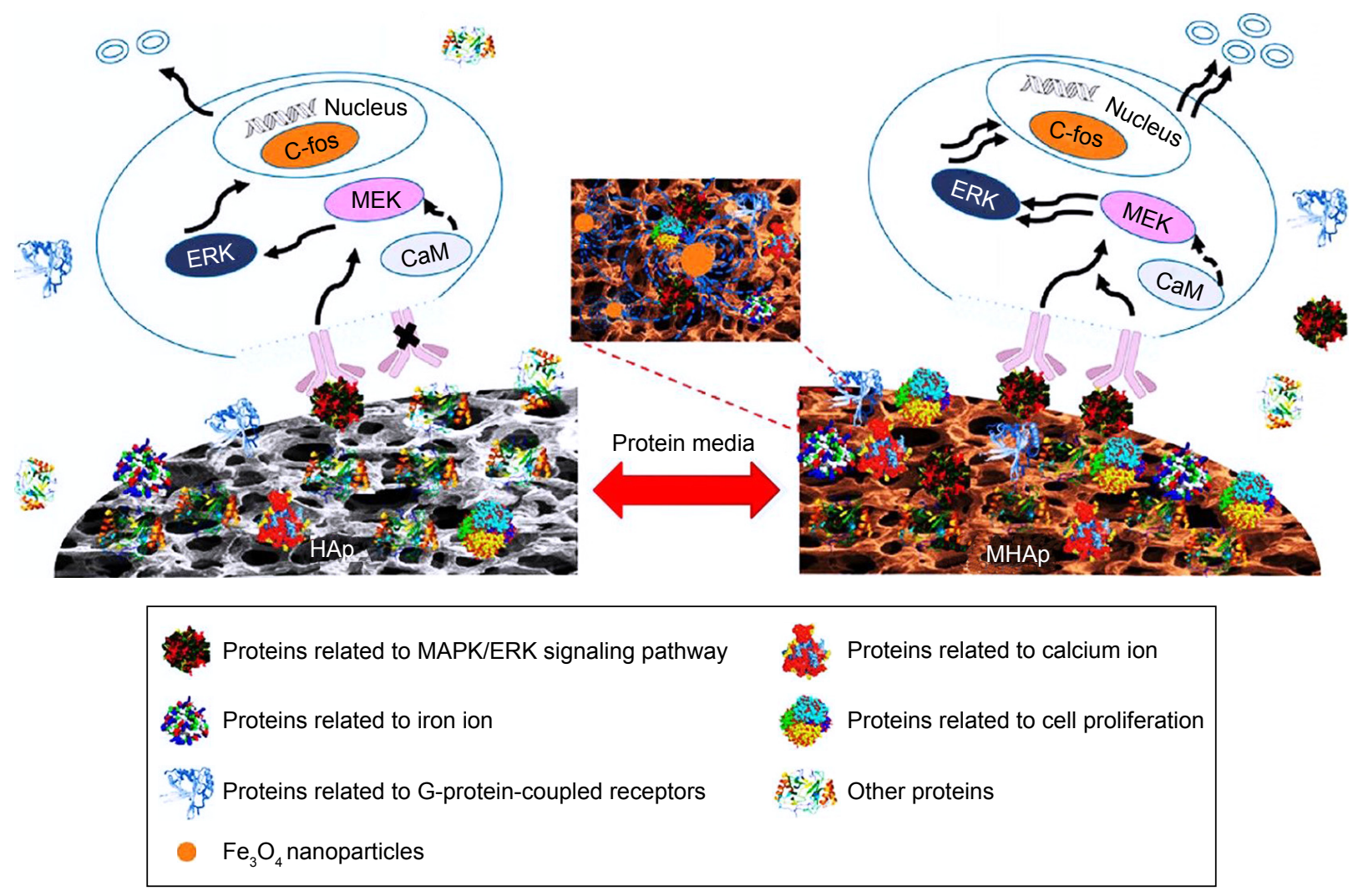

Figure 6 Schematic diagram of MHAp scaffold-enhanced MC3T3-EI cell proliferation, showing that MAPK/ERK signaling pathway was activated by the protein corona formed on the surface of MHAp scaffold to promote cell proliferation. Reprinted with permission from Zhu Y, Yang Q, Yang M, et al. Protein corona of magnetic hydroxyapatite scaffold improves cell proliferation via activation of mitogen-activated protein kinase signaling pathway. ACS Nano. 20I7; I (4):3690-3704. Copyright 20I7 American Chemical Society. ${ }^{101}$

Abbreviations: MHAp, magnetic hydroxyapatite; HAp, hydroxyapatite.

of cell proliferation by MHAp was revealed. This study will definitely help in understanding the scaffold-specific cellular activity and in selecting materials for future tissue engineering application. ${ }^{101}$

\section{Drug delivery, imaging, and magnetic hyperthermia}

For drug delivery application, particle sizes should be small enough to be introduced into the blood circulation system, so that they can easily pass through the capillary systems.

Lin et al developed mesoporous hollow MHAp microstructure by hydrothermal treatment for $\mathrm{pH}$-responsive drug delivery application. With $50 \%$ of magnetite-loaded scaffold, the maximum magnetic saturation obtained was $\sim 58.78 \mathrm{emu} / \mathrm{g}$. Vancomycin was used as the model drug, and the maximum drug-loading capacity was 28.84-35.92 $\mathrm{mg} / \mathrm{g}$ on mesoporous hollow MHAp. A drug release study was performed at different $\mathrm{pH}$ of 3.4, 5.4, and 7.4. During the first $9 \mathrm{~h}, 19 \%$ of drug was released because of the burst effect, and the subsequent release remarkably decreased by
$26 \%-29 \%$ on the next 2 days at $\mathrm{pH} 7.4$. At $\mathrm{pH} 3.4$, the release of loaded vancomycin was maximum at $\sim 70 \mathrm{wt} . \%$, whereas at $\mathrm{pH} 5.4$, the final release capacity was $\sim 40 \mathrm{wt} \%$. This study concluded that with decreasing $\mathrm{pH}$, the drug release efficiency increased, which indicated a suitable condition for magnetic-guided $\mathrm{pH}$-responsive drug delivery. ${ }^{89}$

Chen et al synthesized an MHAp ultrathin nanosheet via a microwave-assisted rapid synthesis route for $\mathrm{pH}$-responsive drug and protein delivery. In this study, docetaxel (Dtxl) and hemoglobin $(\mathrm{Hb})$ were used as model drugs which were adsorbed on the high surface area of nanosheet $\left(\sim 92.8 \mathrm{~m}^{2} / \mathrm{g}\right.$, calculated by the Brunauer-Emmett-Teller analysis). The maximum concentration of $\mathrm{Hb}$ adsorbed was $150 \mathrm{mg} / \mathrm{g}$, and the maximum release was about $84.1 \%$ during the 8 -hour study. In contrast, the Dtxl-loading capacity of the MHAp nanocomposite was $\sim 56 \mathrm{mg} / \mathrm{g}$, and the release rate was regulated by two $\mathrm{pH}$ parameters $(\mathrm{pH} 7.4$ and $\mathrm{pH} 4.5)$. At $\mathrm{pH} 7.4$, $\sim 30 \%$ of the drug was released, whereas at $\mathrm{pH} 4.5, \sim 98 \%$ of the drug was released during the 108-hour study (Figure 7A and $\mathrm{B})$. Because of a well-regulated $\mathrm{pH}$-responsive drug delivery 

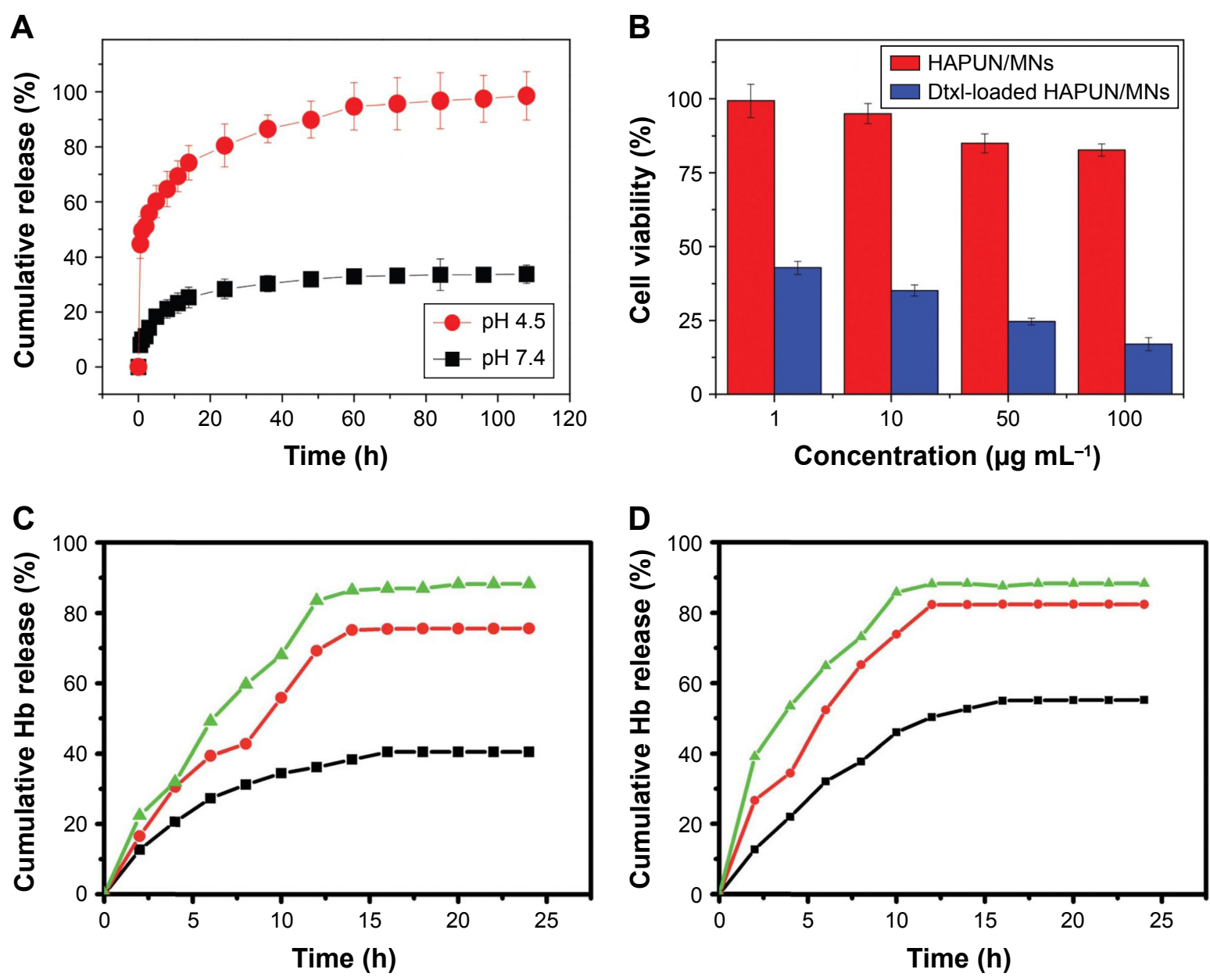

$\rightarrow-\mathrm{pH} 9.0 \rightarrow \mathrm{pH} 7.4-\Lambda-\mathrm{pH} 4.0$

Figure 7 Drug and protein release kinetics of different MHAp nanostructures at different $\mathrm{pH}$ conditions. (A) The cumulative drug release percentages of docetaxel from the HAPUN/MNs nanocomposite drug delivery system in PBS with different pH values of 7.4 and 4.5. Reproduced from Chen F, Li C, Zhu YJ, Zhao XY, Lu BQ, Wu J. Magnetic nanocomposite of hydroxyapatite ultrathin nanosheets $/ \mathrm{Fe}_{3} \mathrm{O}_{4}$ nanoparticles: microwave-assisted rapid synthesis and application in pH-responsive drug release. Biomater $\mathrm{Sci}$. 2013; I (10): 1074-108I with permission of The Royal Society of Chemistry. ${ }^{78}$ (B) Cell viability tests of the HAPUN/MNs without and with docetaxel drug loading. Reproduced from Chen F, Li C, Zhu YJ, Zhao XY, Lu BQ, Wu J. Magnetic nanocomposite of hydroxyapatite ultrathin nanosheets/Fe $\mathrm{O}_{4}$ nanoparticles: microwave-assisted rapid synthesis and application in $\mathrm{pH}$-responsive drug release. Biomater Sci. 2013; I (10): 1074-108I with permission of The Royal Society of Chemistry. ${ }^{78}$ Cumulative release of hemoglobin loaded on (C) $\mathrm{Fe}_{3} \mathrm{O}_{4} / \mathrm{HAp}-\mathrm{I}$ and (D) $\mathrm{Fe}_{3} \mathrm{O}_{4} / \mathrm{HAp}-2$ nanocomposites at different initial pH values of 7.4 and 9.0 in PBS at room temperature. Reproduced from Bharath $\mathrm{G}$, Prabhu D, Mangalaraj D, Viswanathan C, Ponpandian N. Facile in situ growth of $\mathrm{Fe}_{3} \mathrm{O}_{4}$ nanoparticles on hydroxyapatite nanorods for $\mathrm{pH}$ dependent adsorption and controlled release of proteins. RSC Adv. 2014;4(92):50510-50520 with permission of The Royal Society of Chemistry. ${ }^{77}$

Abbreviations: MHAp, magnetic hydroxyapatite; PBS, phosphate buffer solution; HAp, hydroxyapatite; Hb, hemoglobin; Dtxl, docetaxel; HAPUN/MN, HAp ultrathin nanosheet.

and high biocompatibility, this MHAp ultrathin nanocomposite will be an ideal drug delivery agent for cancer treatment. ${ }^{78}$

Bharath et al reported the synthesis of two different MHAp nanorods (two different concentrations of iron loading on HAp) for $\mathrm{pH}$-controlled protein transport by means of protein adsorption and release. The detailed MHAp nanorod synthesis procedure using different synthesis routes is discussed in the earlier section. In this study, $\mathrm{Hb}$ was used as the model protein, the maximum adsorption of which was reported to be $200.07 \mathrm{mg} / \mathrm{g}$. The researchers revealed that increased MNP concentration increased the protein adsorption capacity. The phosphate buffer solution (PBS) of different $\mathrm{pH}$ values (4.0, 7.4, and 9.0) was employed to study the protein release kinetics during $25 \mathrm{~h}$ of the total study period (Figure 7C and D). The maximum protein release $(\sim 87 \%-95 \%)$ was observed at $\mathrm{pH} 4.0$ for synthesized MHAp nanorods. This excellent $\mathrm{pH}$-sensitive protein release property will help in transporting drugs and releasing them at tumor- or cancer-specific target cell sites. ${ }^{77}$

Chen et al studied the use of multifunctional $\mathrm{Eu}^{3+} / \mathrm{Gd}^{3+}$ dual-doped HAp nanorods for in vivo imaging of nude mice with computed tomography (CT) for monitoring the release and distribution of ibuprofen at the injected sites (Figure 8). ${ }^{102}$ A similar study was done by Pan et al with iron oxide-coated 

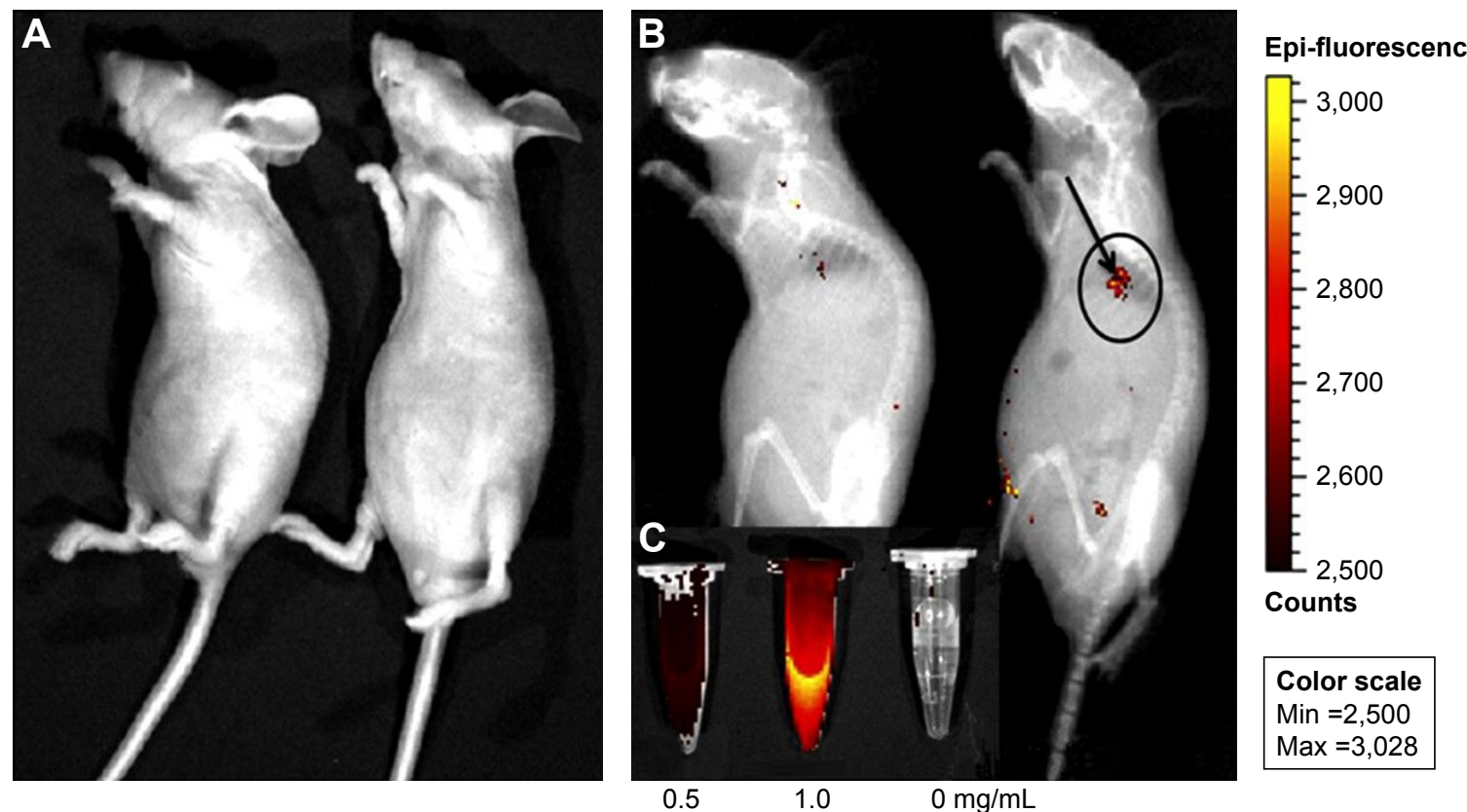

Figure 8 In vivo PL imaging of the mice after subcutaneous injection (A) without and (B) with $\mathrm{Eu}^{3+} / \mathrm{Gd}^{3+}-\mathrm{HAp}\left(\mathrm{Eu}^{3+}: \mathrm{Gd}^{3+}=\mathrm{I:2}\right)$ nanorods. $(\mathbf{C}) \mathrm{PL}$ emission images of $\mathrm{Eu}^{3+} / \mathrm{Gd}^{3+}-\mathrm{HAp}$ nanorods at different concentrations. The excitation wavelength was $430 \mathrm{~nm}$. Reprinted from Chen F, Huang P, Zhu YJ, Wu J, Zhang CL, Cui DX. The photoluminescence, drug delivery and imaging properties of multifunctional Eu+3 $\mathrm{Gd}^{3+}$ dual-doped hydroxyapatite nanorods. Biomaterials. 20I I;32(34):903 I-9039. Copyright 2011 with permission from Elsevier. ${ }^{102}$

Abbreviations: PL, photoluminescence; HAp, hydroxyapatite.

fluoridated $\mathrm{HAp} / \mathrm{Ln}^{3+}(\mathrm{Ln}=\mathrm{Eu}$ or $\mathrm{Tb})$ nanocomposites for biological applications. ${ }^{103}$ Due to isotropic electronic groundstate ${ }^{8} \mathrm{~S}_{7 / 2}$ and half-filled $f$-orbitals, both the trivalent gadolinium and europium ions retained a high magnetic moment and proton relaxation (both transverse and longitudinal) even at low magnetic fields. These electronic structures of rare earth ions make doped MHAp nanostructures an ideal biomarker for MRI and CT scan. ${ }^{102}$

$\mathrm{Xu}$ et al reported a novel synthesis method for magnetic functionalized HAp nanocomposites (MHAp nanoworms) for magnetic resonance diagnosis of the acute hepatic injury. The detailed four-stage fabrication of MHAp nanoworms is discussed in the previous section. The fabrication methodology associated with layer-by-layer modifications with chitosan and sodium alginate enhanced solubility and biocompatibility. The incorporation of iron oxide nanocrystals resulted in the improved performance of MRI. The study was further extended to intravenous injection of MHAp nanoworms, to study the contrast-to-noise ratio of hepatic in vivo MRI (Figure 9). The improved MRI clearly distinguished the hepatic injury grading which indicated the future use of this synthesized material as a potential contrast agent for MRI. ${ }^{76}$

Tampieri et al reported the doping of $\mathrm{Fe}^{2+} / \mathrm{Fe}^{3+}$ on HAp nanostructures for synthesizing MHAp nanoparticles for biomedical applications. The authors aimed to study the potential application of developed nanoparticles using magnetic hyperthermia to treat cancers and to use materials in magnetic scaffolds for tissue engineering application. The hyperthermia study of developed MHAp nanoparticles showed a temperature increase of $40^{\circ} \mathrm{C}$ in $60 \mathrm{~s}$ when exposed to alternating magnetic field (hyperthermia). ${ }^{5}$

Hou et al reported the in vivo performance of synthesized MHAp nanoparticles in hyperthermia therapy for treating cancer in mouse model. MHAp synthesized by co-precipitation method with the addition of $\mathrm{Fe}^{2+}$ and pure HAp nanoparticles were mixed with PBS. This mixture was then injected into the tumor region. The hyperthermia treatment was initiated by placing the mouse into an inductive heater with an applied alternating magnetic field. The 15-day treatment period revealed that the mouse injected with only MHAp showed a dramatic reduction of tumor volume (Figure 10). The blood cytotoxicity study of the mouse showed that MHAp nanoparticles have good biocompatibility with very less toxicity when subcutaneously injected. ${ }^{69}$

Kamitakahara et al successfully synthesized spherical HAp granules that contained composites of magnetic and HAp nanoparticles via a hydrothermal process. ${ }^{104}$ The obtained composite nanoparticles were expected to generate enough heat to kill cancer cells under an alternating magnetic field. The authors assessed hyperthermia using a model experiment, in which synthesized nanoparticles were dispersed in an agar gel solution and an alternating magnetic 

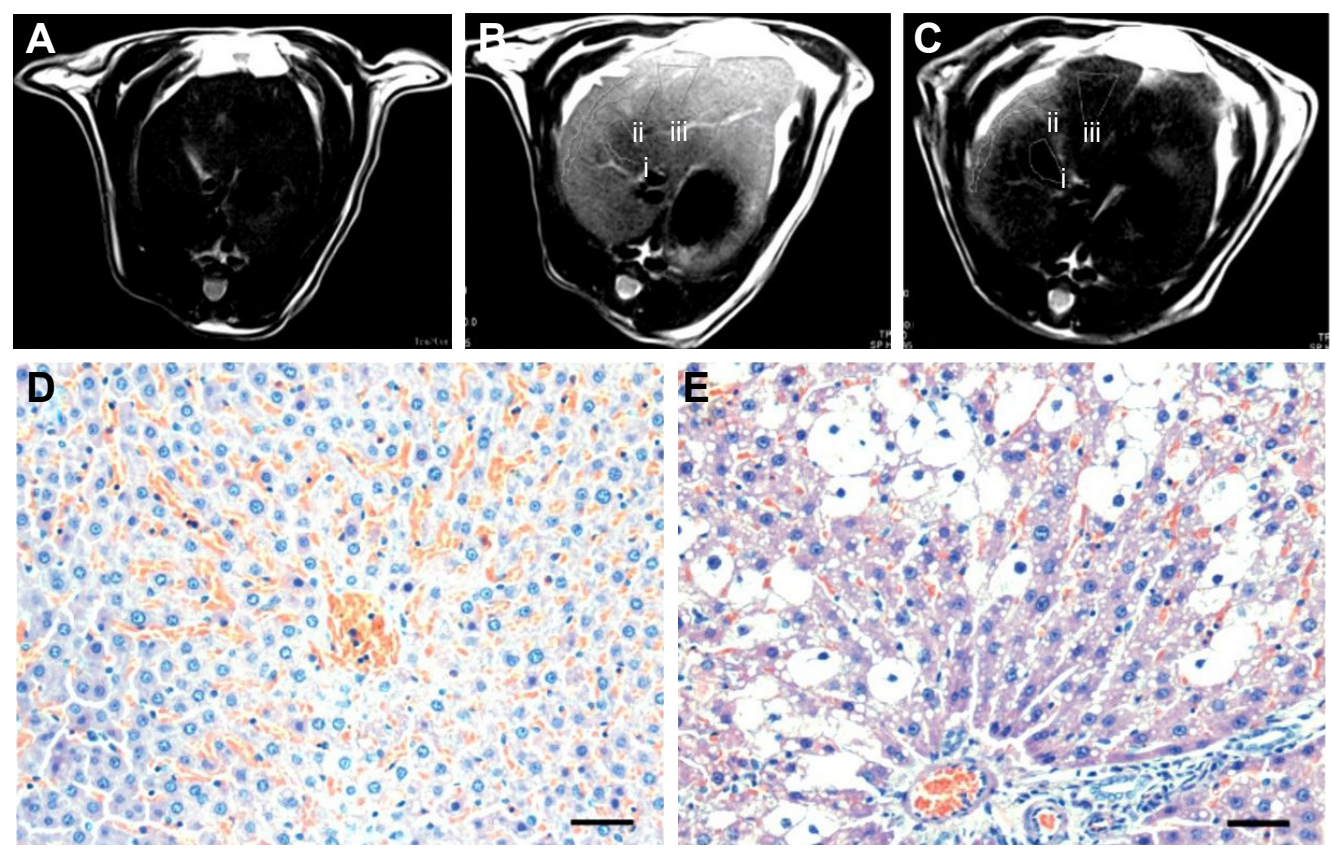

Figure 9 T2-weighted MR images of liver: (A) stage I, normal liver, (B) stage II, acute hepatic injury which is $4 \mathrm{~h}$ after CCl, gavage, and (C) stage III, with the contrast enhancement of the HAp-ION-90 nanoworm. Histochemical analysis of (D) normal hepatic area and (E) injured hepatic area. All scale bars: $20 \mu \mathrm{m}$. Reproduced from Xu YJ, Dong L, Lu Y, et al. Magnetic hydroxyapatite nanoworms for magnetic resonance diagnosis of acute hepatic injury. Nanoscale. 20I6;8(3):1684-I690 with permission of The Royal Society of Chemistry. ${ }^{76}$

Abbreviations: MR, magnetic resonance; HAp, hydroxyapatite; i, Stage I; ii, Stage II; iii, Stage III.

field of 300 Oe at $100 \mathrm{kHz}$ was used. Because of the generated hyperthermia effect, the temperature increased to more than $45^{\circ} \mathrm{C}$ within a very short time period of $80 \mathrm{~s}$.

\section{Gene, protein, and plasmid delivery}

In the last century, the delivery of genetic materials, such as DNA, RNA, proteins, and plasmids, was considered to be complex and be helpful for controlling, protecting, or enriching the biological property of living beings. Hopefully, the present era establishes distinctive controls and improves human life by using different new technologies such as recombinant DNA technology. This technology helps in improving the genetic property by directly delivering new proteins, genes, or plasmids to the target site. There are many technologies associated with delivery of genes, proteins, or plasmids, but in this review we mainly focus on magnetic field-assisted delivery (magnetofection) via MHAp nanoparticles (Figure 10). The suitability and advantages of MHAp nanoparticles are also discussed. In the year 2000, Mah et al first reported regarding the magnetic microparticleassociated genetic material transfer, which helped improve transduction efficiency. ${ }^{105}$

Different strategies, including use of cleavable linkers, electrostatic interactions, and integration of vector with degradable property, could be executed after targeting specific cells. The most promising approaches for binding genetic
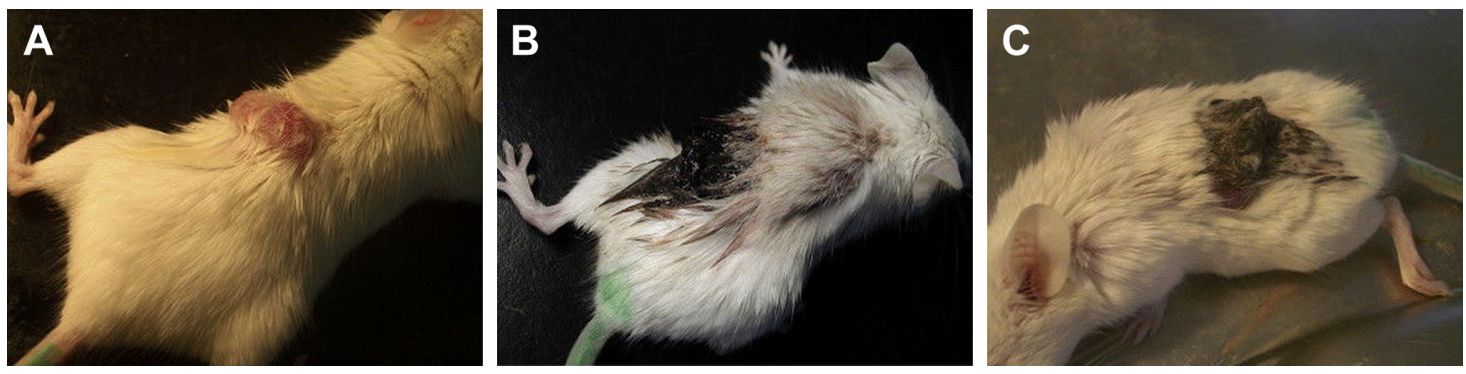

Figure 10 The clinical photographs of the mouse treated with MHAp on magnetic field exposure. The tumor on (A) day I, (B) day 5 , and (C) day I4 is shown. Reprinted from Hou CH, Hou SM, Hsueh YS, Lin J, Wu HC, Lin FH. The in vivo performance of biomagnetic hydroxyapatite nanoparticles in cancer hyperthermia therapy. Biomaterials. 2009;30(23-24):3956-3960. Copyright 2009, with permission from Elsevier. ${ }^{69}$

Abbreviation: MHAp, magnetic hydroxyapatite. 
materials to the surface of magnetic particles are based on electrostatic interactions. Here, the coating of HAp plays a key role and gives the added advantage over conventional coating materials. Most importantly, the nontoxic HAp surface exhibits a tunable property that allows to change its surface charge (positive, negative, or neutral) by very simple modifications (eg, aminododecanoic acid); moreover, a large number of target molecules have good affinity and adherence to the HAp surface. ${ }^{106}$

Shan et al attempted to formulate HAp-iron oxide nanocomposites to reduce the complexity of the purification of pDNA from crude Escherichia coli lysates. DNA is expected to bind with HAp, and this binding involves the phosphate bond moieties of DNA and the surface calcium sites of HAp. The binding efficiency of DNA and MHAp in pure water was $0.42 \mu \mathrm{g} \mathrm{pDNA} / \mathrm{mg} \mathrm{MHAp}$, and the static binding efficiency in sodium acetate solution was $3.96 \mu \mathrm{g} \mathrm{pDNA} / \mathrm{mg}$ MHAp at $10 \mathrm{mM}$. This method of MHAp synthesis is simple, fast, and cost-effective without the requirement of further purification via centrifugation and hazardous chemical solvents. ${ }^{66}$

A

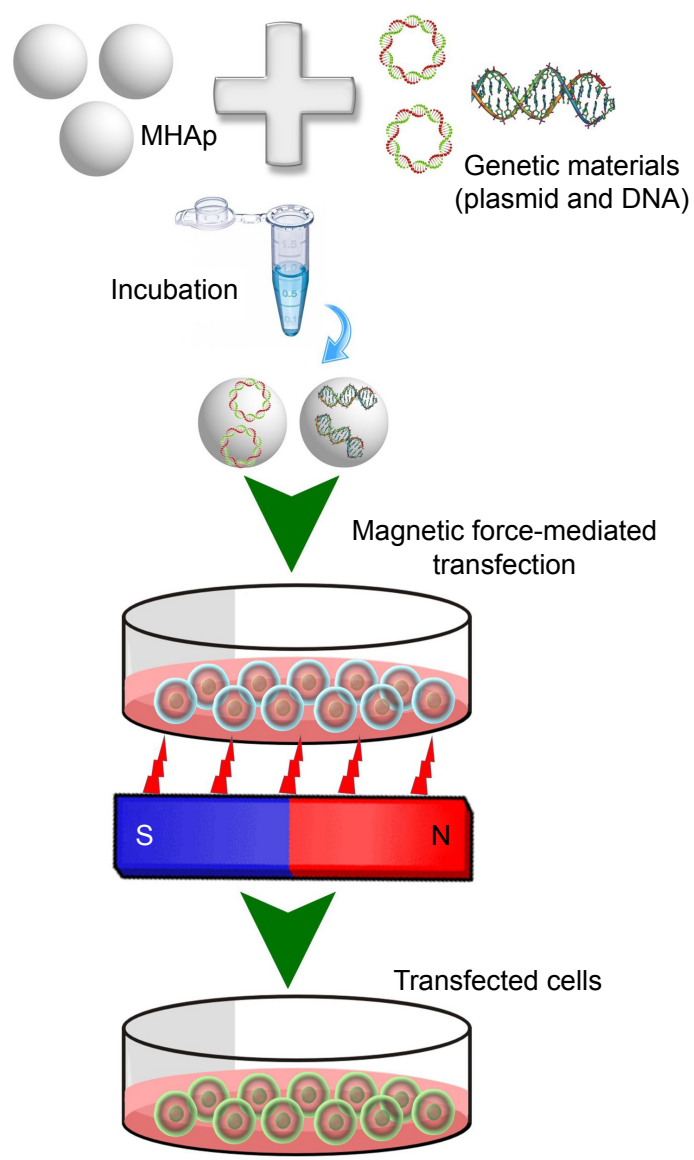

Zuo et al synthesized laminated MHAp/DNA nanohybrid using a solution intercalation method. The prepared laminated MHAp exhibited an effective DNA-protecting property. The laminated MHAp preparation method is already described in the previous synthesis section. After the intercalation of salmon sperm DNA, the size expansion study of laminated MHAp (from 3.1 to $3.8 \mathrm{~nm}$ ) proved the DNA attachment. The authors reported the DNA-protecting property of laminated MHAp during the exposure of attached DNA to DNase I enzyme. This laminated MHAp has prospective application in gene therapy because of its stable protective behavior. ${ }^{67}$

Wu and Lin synthesized MHAp nanoparticles by adding iron into HAp using wet precipitation method. MHAp nanoparticles have a binding affinity to pDNA to form a transfection composite. Three different transfection approaches have been studied, namely 1) traditional transfection without a magnetic field (as the control), 2) combined transfection with application of a magnetic field for initial $15 \mathrm{~min}$, and 3) a combined transfection with a $4 \mathrm{~h}$ co-culture (during co-culture, a magnetic field was applied for $5 \mathrm{~min}$ in each
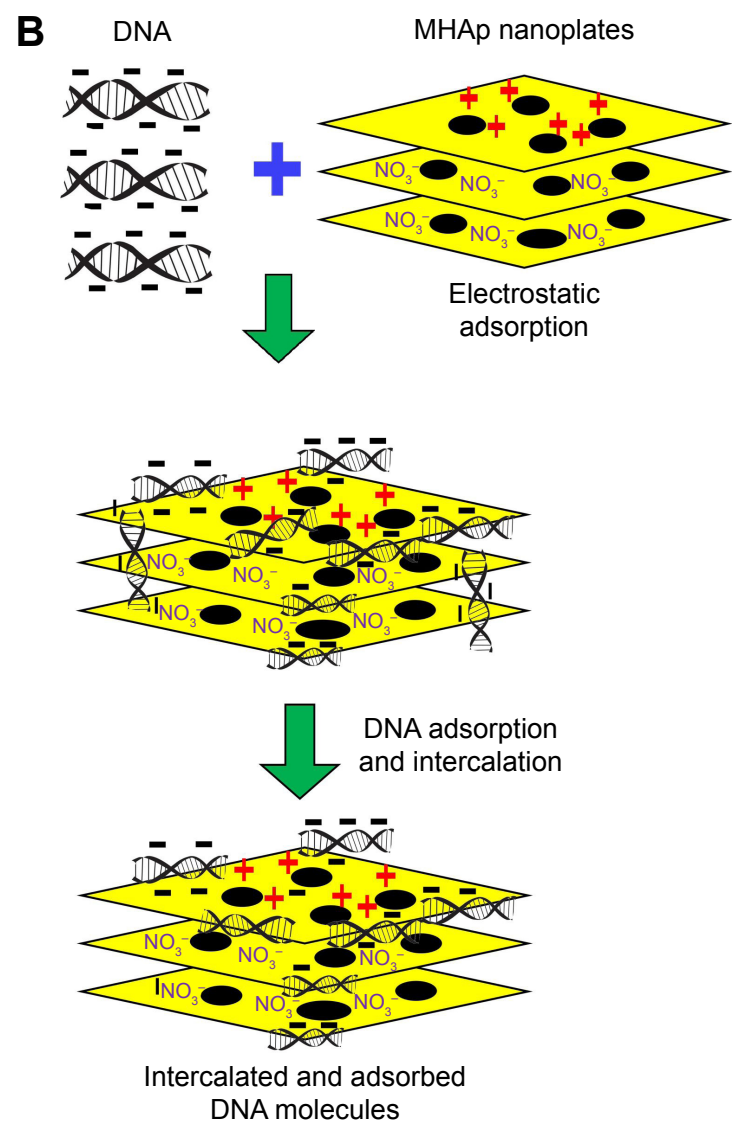

Figure II (A) Schematic representation of magnetofection for gene delivery. (B) Schematic illustration of DNA loading into lamellar MHAp nanoparticles for nucleic acid delivery.

Abbreviation: MHAp, magnetic hydroxyapatite. 
Table 4 A list of granted patents on MHAp nanomaterials during 20I0-20I7

\begin{tabular}{|c|c|c|c|}
\hline S no & Patents (application potentials) & Number and grant date & Application area \\
\hline I & Magnetic nano-hydroxyapatite adsorbent, preparation and application thereof & CNI0I7039I7A (May I2, 2010) & Environmental \\
\hline 2 & $\begin{array}{l}\text { Biodegradable macromolecule composite material with shape memory function } \\
\text { and its preparation method and use }\end{array}$ & CNI0I240II6B (Mar 30, 20II) & Biomedical \\
\hline 3 & $\begin{array}{l}\text { Ordered porous magnetic hydroxyapatite material, preparation method thereof } \\
\text { and applications }\end{array}$ & CNI0I337665B (Apr 06, 20II) & Biomedical \\
\hline 4 & $\begin{array}{l}\text { Method for preparing magnetic fluorescence hydroxyapatite nanocomposite } \\
\text { structure }\end{array}$ & CNI02020258A (Apr 20, 20II) & Biomedical \\
\hline 5 & $\begin{array}{l}\text { Magnetic cationic surfactant-modified chitosan/hydroxyapatite/zeolite composite } \\
\text { and preparation method and application thereof }\end{array}$ & CNI02500333A (Jun 20, 20I2) & Environmental \\
\hline 6 & Method for preparing magnetic hydroxyapatite nanotubes & KR20I20068802A (Nov I3, 20I3) & $\begin{array}{l}\text { Biomedical and } \\
\text { environmental }\end{array}$ \\
\hline 7 & Coliform detection process and kit for use therein & US874I595B2 (Jun 03, 2014) & Biomedical \\
\hline 8 & Coated metal powder, powder magnetic core, and a process for their production & JP5565595B2 (Aug 06, 20I4) & Biomedical \\
\hline 9 & Preparation and application of magnetic hydroxyapatite/graphene oxide adsorbent & CNI04289I8IA (Jan 2I, 20I5) & Environmental \\
\hline 10 & Underground water fluoride-removing device based on magnetic hydroxyapatite & CNI04386859A (Mar 04, 2015) & Environmental \\
\hline 11 & $\begin{array}{l}\text { Magnetic nanoporous composite bone tissue engineering support material and } \\
\text { preparation method thereof }\end{array}$ & CNI03480044B (May 06, 20I5) & Biomedical \\
\hline 12 & $\begin{array}{l}\text { Preparation method of magnetic, luminescent bifunctional core-shell structure } \\
\text { nano-hydroxyapatite particles }\end{array}$ & CNI03820I02B (Apr 13, 2016) & Biomedical \\
\hline 13 & Intrinsically magnetic hydroxyapatite & USI38I274I (May 03, 20I6) & Biomedical \\
\hline 14 & A magnetic ball of hydroxyapatite whisker preparation method & CNI0354I005B (Jun 22, 20I6) & $\begin{array}{l}\text { Biomedical and } \\
\text { environmental }\end{array}$ \\
\hline 15 & Biomedical materials & US956I960B2 (Feb 07, 20I7) & Biomedical \\
\hline
\end{tabular}

Abbreviation: MHAp, magnetic hydroxyapatite.

hour). pDNA-MHAp nanoparticles showed an increase in gene delivery efficacy across the cell membrane and demonstrated specific localization under the control of a magnetic field. Based on this study, MHAp nanoparticles were confirmed to have good potential as a nonviral vector for gene delivery. ${ }^{107}$

Xiong et al synthesized lamellar MHAp nanoparticles by template-assisted self-assembly procedure, the DNA loading and transfection efficiencies of which were compared with those of HAp lamellar nanostructures without magnetite. The MHAp lamellar structure showed 47\% more (14.16\% compared to $9.64 \%$ ) transfection efficiency. The mouse L929 fibroblast cell line was used for transfection and cell cytotoxicity study. In their study, zeta $(\zeta)$ potential was critically evaluated, and the authors concluded that a higher $\zeta$-potential results in a higher transfection efficiency. The synthesized lamellar MHAp is a promising magnetic-guided gene delivery agent for a new-generation virus-free transfection method (Figure 11). ${ }^{68}$

\section{Scope of future applications}

The nature of surface modifications and their consequent geometric orientation on the nanoparticles crucially determine the sizes and shapes of these nanoparticles, and also play a significant role in their biokinetics and biodistribution inside the body system. To this end, most studies have focused on improving the biocompatibility of materials, but very few scientific studies have reported the refining of magnetic particles after coating or formation of a composite structure. After the surface modification of MHAp nanoparticle, the saturation magnetization dramatically decreased. For a medical-grade drug delivery agent, a better method needs to be identified for improving the magnetic property while ensuring that the other characteristics are unaffected. Important applications, including many interesting biomedicinal uses of MHAp, have already been discussed. Different facile synthetic routes and their mode of action, as well as close integration with surrounding molecules, need to be evaluated in a more comprehensive study. More critical studies are warranted to formulate more cost-effective but good-quality MHAp nanoparticles without any protracted purification stages. In vivo and analytical applications need specific MHAp particles with predefined properties (quantity, geometric arrangement, etc.). The safety and biocompatibility of MHAp nanoparticles need to be assessed over a long time duration prior to applications in human, and hence, more in-depth toxicity studies should be conducted. Futuristic nanotechnology will also perceive medical prosthetics as another sector for improved biomedical implants such as multifunctional drug-loaded implants with external magnetic control. 
The potentials of MHAp nanoparticles in biomedical and environmental applications that have been emphasized in a vast number of recent publications and demonstrated through filed and offered patents particularly during the last 7 years (2010-2017) are enlisted in Table 4.

\section{Conclusion}

This review on the nano-biomedical applications of nanoparticles focuses on tailoring new materials through facile synthetic methods or refining conventional synthetic routes to obtain reproducible MHAp nanoparticles with optimum morphology (shape and size), stability, and biocompatibility, in addition to superior magnetic saturation. The ultimate goal of using MHAp in biomedicine is to help patients, by introducing selective treatments through guided drug delivery systems. In addition to drug delivery, the use of multifunctional MHAp in simultaneous imaging, hyperthermia, and gene/plasmid delivery is going to drastically improve the diagnosis and therapy of diseases. HAp coating over magnetic nanoparticles offers several advantages such as excellent biocompatibility and high stability in a broad $\mathrm{pH}$ and temperature range; moreover, it protects nanoparticles such as polymers from agglomeration. The stability of HAp at high $\mathrm{pH}$ range helps in regulating drug release kinetics during a pH-mediated drug delivery inside the body system. In regenerative tissue engineering applications, using MHAp nanoparticles to prepare scaffold materials stimulates remote actuation for regulating bioactive molecules and magneto-mechanical cell stimulation, cell seeding, and cell patterning. Besides the advances, the exhilarating milestones made in these areas seek attention for critical evaluation before being regularized in the medical sector. However, we trust that the coming few years will see huge advances in the number of MHAp-based diagnostics and medicines being used in the clinics. This review critically revealed the recent status, efficiency, and future prospects of MHAp nanomaterials in biomedical applications.

\section{Acknowledgment}

This review was supported by a grant from Marine Biotechnology Program (20150220) funded by the Ministry of Oceans and Fisheries, Republic of Korea.

\section{Disclosure}

The authors declare no conflicts of interest in this work.

\section{References}

1. Freeman MW, Arrott A, Watson HL. Magnetism in medicine. J Appl Phys. 1960;31:404S-405S.
2. Pankhurst QA, Connolly J, Jones SK, Dobson J. Applications of magnetic nanoparticles in biomedicine. J Phys D Appl Phys. 2003;36:R167-R181.

3. Polyak B, Friedman G. Magnetic targeting for site-specific drug delivery: applications and clinical potential. Expert Opin Drug Deliv. 2009;6(1):53-70.

4. Trandafir DL, Mirestean C, Turcu RVF, Frentiu B, Eniu D, Simon S. Structural characterization of nanostructured hydroxyapatite-iron oxide composites. Ceram Int. 2014;40:11071-11078.

5. Tampieri A, D'Alessandro T, Sandri M, et al. Intrinsic magnetism and hyperthermia in bioactive Fe-doped hydroxyapatite. Acta Biomater. 2012;8(2):843-851.

6. Tseng CL, Chang KC, Yeh MC, Yang KC, Tang TP, Lin FH. Development of a dual-functional Pt-Fe-HAP magnetic nanoparticles application for chemo-hyperthermia treatment of cancer. Ceram Int. 2014; 40(4):5117-5127.

7. Pon-On W, Meejoo S, Tang IM. Substitution of manganese and iron into hydroxyapatite: core/shell nanoparticle. Mater Res Bull. 2008; 43(8-9):2137-2144.

8. Petchsang N, Pon-On W, Hodak JH, Tang IM. Magnetic properties of Co-ferrite-doped hydroxyapatite nanoparticles having a core/shell structure. J Magn Magn Mater. 2009;321(13):1990-1995.

9. Syamchand SS, Sony G. Multifunctional hydroxyapatite nanoparticles for drug delivery and multimodal molecular imaging. Microchimica Acta. 2015;182(9-10):1567-1589.

10. Liu Y, Sun Y, Cao C, et al. Long-term biodistribution in vivo and toxicity of radioactive/magnetic hydroxyapatite nano rods. Biomaterials. 2014;35(10):3348-3355.

11. Kuda O, Pinchuk N, Iyanchenko L, et al. Effect of $\mathrm{Fe}_{3} \mathrm{O}_{4}, \mathrm{Fe}$ and $\mathrm{Cu}$ doping on magnetic properties and behaviour in physiological solution of biological hydroxyapatite/glass composite. J Mater Process Technol. 2009;209(4):1960-1964.

12. Mahdavi M, Ahmad MB, Haron MJ, et al. Synthesis, surface modification and characterisation of biocompatible magnetic iron oxide nanoparticles for biomedical applications. Molecules. 2013;18(7):7533-7548.

13. Iafisco M, Sandri M, Panseri S, Delgado-López JM, Gómez-Morales J, Tampieri A. Magnetic bioactive and biodegradable hollow Fe-doped hydroxyapatite coated poly(l-lactic) acid micro-nanospheres. Chem Mater. 2013;25(13):2610-2617.

14. Taccola S, Desi A, Pensabene V, et al. Free-standing poly(l-lactic acid) nanofilms loaded with superparamagnetic nanoparticles. Langmuir. 2011;27(9):5589-5595.

15. Padwal P, Bandyopadhyaya R, Mehra S. Polyacrylic acid-coated iron oxide nanoparticles for targeting drug resistance in mycobacteria. Langmuir. 2014;30(50):15266-15276.

16. Ma YH, Wu SY, Wu T, Chang YJ, Hua MY, Chen JP. Magnetically targeted thrombolysis with recombinant tissue plasminogen activator bound to polyacrylic acid-coated nanoparticles. Biomaterials. 2009; 30(19):3343-3351.

17. Denizot B, Tanguy G, Hindre F, Rump E, Jacques Le Jeune J, Jallet P. Phosphorylcholine coating of iron oxide nanoparticles. J Colloid Interface Sci. 1999;209(1):66-71.

18. Liu HL, Ko SP, Wu JH, et al. One-pot polyol synthesis of monosize PVP-coated sub-5 $\mathrm{nm} \mathrm{Fe}_{3} \mathrm{O}_{4}$ nanoparticles for biomedical applications. J Magn Magn Mater. 2007;310(2 Pt 3):e815-e817.

19. Mahmoudi M, Simchi A, Imani M, Milani AS, Stroeve P. Optimal design and characterization of superparamagnetic iron oxide nanoparticles coated with polyvinyl alcohol for targeted delivery and imaging. J Phys Chem B. 2008;112(46):14470-14481.

20. Hou R, Zhang G, Du G, et al. Magnetic nanohydroxyapatite/PVA composite hydrogels for promoted osteoblast adhesion and proliferation. Colloids Surf B Biointerfaces. 2013;103:318-325.

21. Mir A, Mallik D, Bhattacharyya S, Mahata D, Sinha A, Nayar S. Aqueous ferrofluids as templates for magnetic hydroxyapatite nanocomposites. J Mater Sci Mater Med. 2010;21(8):2365-2369.

22. Nadeem M, Ahmad M, Akhtar MS, et al. Magnetic properties of polyvinyl alcohol and doxorubicine loaded iron oxide nanoparticles for anticancer drug delivery applications. PLoS One. 2016;11(6):e0158084. 
23. Sun C, Veiseh O, Gunn J, et al. In vivo MRI detection of gliomas by chlorotoxin conjugated superparamagnetic nanoprobes. Small. 2008;4(3):372-379.

24. Nazli C, Ergenc TI, Yar Y, Acar HY, Kizilel S. RGDS-functionalized polyethylene glycol hydrogel-coated magnetic iron oxide nanoparticles enhance specific intracellular uptake by HeLa cells. Int J Nanomedicine. 2012;7:1903-1920.

25. Jarrett BR, Frendo M, Vogan J, Louie AY. Size-controlled synthesis of dextran sulfate coated iron oxide nanoparticles for magnetic resonance imaging. Nanotechnology. 2007;18(3):35603.

26. Yu M, Huang S, Yu KJ, Clyne AM. Dextran and polymer polyethylene glycol (PEG) coating reduce both 5 and $30 \mathrm{~nm}$ iron oxide nanoparticle cytotoxicity in 2D and 3D cell culture. Int J Mol Sci. 2012;13(5): 5554-5570.

27. Wahajuddin, Arora S. Superparamagnetic iron oxide nanoparticles: magnetic nanoplatforms as drug carriers. Int J Nanomedicine. 2012;7: 3445-3471.

28. Saboktakin MR, Maharramov A, Ramazanov MA. Synthesis and characterization of superparamagnetic nanoparticles coated with carboxymethyl starch (CMS) for magnetic resonance imaging technique. Carbohydr Polym. 2009;78(2):292-295.

29. Saikia C, Hussain A, Ramteke A, Sharma HK, Deb P, Maji TK. Carboxymethyl starch-coated iron oxide magnetic nanoparticles: a potential drug delivery system for isoniazid. Iran Polym J. 2015;24(10): 815-828.

30. Ma D, Wasylaschuk WR, Beasley C, et al. Identification and quantitation of extractables from cellulose acetate butyrate (CAB) and estimation of their in vivo exposure levels. J Pharm Biomed Anal. 2004; 35(4):779-788.

31. Bekaroğlu MG, İşçi Y, İşçi S. Colloidal properties and in vitro evaluation of hydroxy ethyl cellulose coated iron oxide particles for targeted drug delivery. Mater Sci Eng C Mater Biol Appl. 2017;78:847-853.

32. Gaihre B, Khil MS, Lee DR, Kim HY. Gelatin-coated magnetic iron oxide nanoparticles as carrier system: drug loading and in vitro drug release study. Int J Pharm. 2009;365(1-2):180-189.

33. Gaihre B, Khil MS, Kang HK, et al. Bioactivity of gelatin coated magnetic iron oxide nanoparticles: in vitro evaluation. J Mater Sci Mater Med. 2009;20(2):573-581.

34. Intorasoot S, Srirung R, Intorasoot A, Ngamratanapaiboon S. Application of gelatin-coated magnetic particles for isolation of genomic DNA from bacterial cells. Anal Biochem. 2009;386(2):291-292.

35. Nguyen VC, Pho QH. Preparation of chitosan coated magnetic hydroxyapatite nanoparticles and application for adsorption of reactive Blue 19 and $\mathrm{Ni}^{2+}$ ions. Sci World J. 2014;2014:273082.

36. Sahoo Y, Pizem H, Fried T, et al. Alkyl phosphonate/phosphate coating on magnetite nanoparticles: a comparison with fatty acids. Langmuir. 2001;17(25):7907-7911.

37. Xie W, Zang X. Covalent immobilization of lipase onto aminopropylfunctionalized hydroxyapatite-encapsulated- $\gamma-\mathrm{Fe}_{2} \mathrm{O}_{3}$ nanoparticles: a magnetic biocatalyst for inter esterification of soybean oil. Food Chem. 2017;227:397-403.

38. Kalidasan V, Liu XL, Herng TS, Yang Y, Ding J. Bovine serum albumin-conjugated ferrimagnetic iron oxide nanoparticles to enhance the biocompatibility and magnetic hyperthermia performance. Nano Micro Lett. 2016;8(1):80-93.

39. Zhang Y, Kohler N, Zhang M. Surface modification of superparamagnetic magnetite nanoparticles and their intracellular uptake. Biomaterials. 2002;23(7):1553-1561.

40. Gupta AK, Berry C, Gupta M, Curtis A. Receptor-mediated targeting of magnetic nanoparticles using insulin as a surface ligand to prevent endocytosis. IEEE Trans Nanobioscience. 2003;2(4):256-261.

41. Liu TY, Huang TC. A novel drug vehicle capable of ultrasound-triggered release with MRI functions. Acta Biomater. 2011;7(11):3927-3934.

42. Silva SM, Tavallaie R, Sandiford L, Tilley RD, Gooding JJ. Gold coated magnetic nanoparticles: from preparation to surface modification for analytical and biomedical applications. Chem Commun. 2016; 52(48):7528-7540.
43. Elsherbini AAM, Saber M, Aggag M, El-Shahawy A, Shokier HAA. Laser and radiofrequency induced hyperthermia treatment via gold-coated magnetic nanocomposites. Int J Nanomedicine. 2011;6:2155-2165.

44. Mahmoudi M, Serpooshan V. Silver-coated engineered magnetic nanoparticles are promising for the success in the fight against antibacterial resistance threat. ACS Nano. 2012;6(3):2656-2664.

45. Kwon D, Lee S, Ahn MM, Kang IS, Park KH, Jeon S. Colorimetric detection of pathogenic bacteria using platinum-coated magnetic nanoparticle clusters and magnetophoretic chromatography. Anal Chim Acta. 2015;883:61-66.

46. Thomas CR, Ferris DP, Lee JH, et al. Noninvasive remote-controlled release of drug molecules in vitro using magnetic actuation of mechanized nanoparticles. J Am Chem Soc. 2010;132(31):10623-10625.

47. Yang P, Quan Z, Hou Z, et al. A magnetic, luminescent and mesoporous core-shell structured composite material as drug carrier. Biomaterials. 2009;30(27):4786-4795.

48. Ye F, Laurent S, Fornara A, et al. Uniform mesoporous silica coated iron oxide nanoparticles as a highly efficient, nontoxic MRI T(2) contrast agent with tunable proton relaxivities. Contrast Media Mol Imaging. 2012;7(5):460-468.

49. Beydoun D, Amal R. Novel photocatalyst: titania-coated magnetite. Activity and photodissolution. J Phys Chem B. 2000;104(18):4387-4396.

50. Pareta RA, Taylor E, Webster TJ. Increased osteoblast density in the presence of novel calcium phosphate coated magnetic nanoparticles. Nanotechnology. 2008;19(26):265101.

51. Mali SA, Nune KC, Misra RDK. Biomimetic nanostructured hydroxyapatite coatings on metallic implant materials. Mater Technol. 2016; 31(13):782-790.

52. Kumar A, Nune KC, Murr LE, Misra RDK. Biocompatibility and mechanical behaviour of three-dimensional scaffolds for biomedical devices: process-structure-property paradigm. Int Mater Rev. 2016; 61(13):20-45.

53. Kumar A, Nune KC, Misra RD. Biological functionality of extracellular matrix-ornamented three-dimensional printed hydroxyapatite scaffolds. J Biomed Mater Res A. 2016;104(6):1343-1351.

54. Depan D, Misra RD. Processing-structure-functional property relationship inorganic-inorganic nanostructured scaffolds for bone-tissue engineering: the response of preosteoblasts. J Biomed Mater Res Part A. 2012;100(11):3080-3091

55. Maganti N, Venkat Surya PKC, Thein-Han WW, Pesacreta TC, Misra RDK. Structure-process-property relationship of biomimetic chitosan-based nanocomposite scaffolds for tissue engineering: biological, physico-chemical, and mechanical functions. Adv Eng Mater. 2011;13(3):B108-B122.

56. Thein-Han WW, Misra RDK. Three-dimensional chitosan-nanohydroxyapatite composite scaffolds for bone tissue engineering. JOM. 2009;61(9):41-44.

57. Kumar A, Misra RDK, Basu B. Structure-property relationship in an electroconductive hydroxyapatite-titanium disilicide composite. Int $J$ Appl Ceram Technol. 2016;13(4):773-786.

58. Depan D, Misra RD. The development, characterization, and cellular response of a novel electroactive nanostructured composite for electrical stimulation of neural cells. Biomater Sci. 2014;2(12): $1727-1739$.

59. Kumar A, Nune KC, Basu B, Misra RD. Mechanistic contribution of electroconductive hydroxyapatite-titanium disilicide composite on the alignment and proliferation of cells. J Biomater Appl. 2016;30(10):1505-1516.

60. Mondal S, Pal U, Dey A. Natural origin hydroxyapatite scaffold as potential bone tissue engineering substitute. Ceram Int. 2016;42: 18338-18346.

61. Mondal S, Mahata S, Kundu S, Mondal B. Processing of natural resourced hydroxyapatite ceramics from fish scale. Adv Appl Ceram. 2010;109(4):234-239.

62. Mondal S, Bardhan R, Mondal B, et al. Synthesis, characterization and in vitro cytotoxicity assessment of hydroxyapatite from different bio sources for tissue engineering application. Bull Mater Sci. 2012; 35(4):683-691. 
63. Mondal S, De Anda Reyes ME, Pal U. Plasmon induced enhanced photocatalytic activity of gold loaded hydroxyapatite nanoparticles under visible light. RSC Adv. 2017;7(14):8633-8645.

64. Mondal S, Mondal B, Dey A, Mukhopadhyay SS. Studies on processing and characterization of hydroxyapatite biomaterials from different bio wastes. J Miner Mater Charact Eng. 2012;11(1):55-67.

65. Wu HS, Wang TW, Sun JS, Wang WH, Lin FH. A novel biomagnetic nanoparticle based on hydroxyapatite. Nanotechnology. 2007; 18(16): 165601.

66. Shan Z, Li X, Gao Y, Wang X, Li C, Wu Q. Application of magnetic hydroxyapatite nanoparticles for solid phase extraction of plasmid DNA. Anal Biochem. 2012;425(2):125-127.

67. Zuo GF, Wan YZ, Hou LY, Zeng XF, Shen Y, Gao GJ. Intercalative nanohybrid of DNA in laminated magnetic hydroxyapatite. Mater Technol. 2015;30(2):86-89.

68. Xiong G, Wan Y, Zuo G, Ren K, Luo H. Self-assembled magnetic lamellar hydroxyapatite as an efficient nanovector for gene delivery. Curr Appl Phys. 2015;15(7):811-818.

69. Hou CH, Hou SM, Hsueh YS, Lin J, Wu HC, Lin FH. The in vivo performance of biomagnetic hydroxyapatite nanoparticles in cancer hyperthermia therapy. Biomaterials. 2009;30(23-24):3956-3960.

70. Laranjeira MS, Moço A, Ferreira J, et al. Different hydroxyapatite magnetic nanoparticles for medical imaging: its effects on hemostatic, hemolytic activity and cellular cytotoxicity. Colloids Surf B Biointerfaces. 2016;146:363-374.

71. Zilm ME, Chen L, Sharma V, et al. Hydroxyapatite substituted by transition metals: experiment and theory. Phys Chem Chem Phys. 2016; 18(24):16457-16465.

72. Iannotti V, Adamiano A, Ausanio G, et al. Fe-doping induced magnetism in nano-hydroxyapatites. Inorg Chem. 2017;56(8):4447-4459.

73. Gambardella A, Bianchi M, Kaciulis S, et al. Magnetic hydroxyapatite coatings as a new tool in medicine: a scanning probe investigation. Mater Sci Eng C Mater Biol Appl. 2016;62:444-449.

74. Tran N, Webster TJ. Increased osteoblast functions in the presence of hydroxyapatite-coated iron oxide nanoparticles. Acta Biomater. 2011; 7(3):1298-1306.

75. Donadel K, Felisberto MD, Laranjei MC. Preparation and characterization of hydroxyapatite-coated iron oxide particles by spray-drying technique. An Acad Bras Ciênc. 2009;81(2):179-186.

76. Xu YJ, Dong L, Lu Y, et al. Magnetic hydroxyapatite nanoworms for magnetic resonance diagnosis of acute hepatic injury. Nanoscale. 2016;8(3):1684-1690.

77. Bharath G, Prabhu D, Mangalaraj D, Viswanathan C, Ponpandian N. Facile in situ growth of $\mathrm{Fe}_{3} \mathrm{O}_{4}$ nanoparticles on hydroxyapatite nanorods for $\mathrm{pH}$ dependent adsorption and controlled release of proteins. $R S C$ Adv. 2014;4(92):50510-50520.

78. Chen F, Li C, Zhu YJ, Zhao XY, Lu BQ, Wu J. Magnetic nanocomposite of hydroxyapatite ultrathin nanosheets $/ \mathrm{Fe}_{3} \mathrm{O}_{4}$ nanoparticles: microwave-assisted rapid synthesis and application in $\mathrm{pH}$-responsive drug release. Biomater Sci. 2013;1(10):1074-1081.

79. Singh RK, El-Fiqi AM, Patel KD, Kim HW. A novel preparation of magnetic hydroxyapatite nanotubes. Mater Lett. 2012;75: 130-133.

80. Iwasaki T, Nakatsuka R, Murase K, Takata H, Nakamura H, Watano S. Simple and rapid synthesis of magnetite/hydroxyapatite composites for hyperthermia treatments via a mechanochemical route. Int J Mol Sci. 2013;14(5):9365-9378.

81. Gopi D, Ansari MT, Shinyjoy E, Kavitha L. Synthesis and spectroscopic characterization of magnetic hydroxyapatite nanocomposite using ultrasonic irradiation. Spectrochim Acta A Mol Biomol Spectrosc. 2012;87:245-250.

82. Gu L, He X, Wu Z. Mesoporous Fe3O4/hydroxyapatite composite for targeted drug delivery. Mater Res Bull. 2014;59:65-68.

83. Manatunga DC, de Silva RM, de Silva KMN, et al. pH responsive controlled release of anti-cancer hydrophobic drugs from sodium alginate and hydroxyapatite bi-coated iron oxide nanoparticles. Eur J Pharm Biopharm. 2017;117:29-38.
84. Ahmadzadeh E, Rowshan FT, Hosseini M. A biological method for in-situ synthesis of hydroxyapatite-coated magnetite nanoparticles using Enterobacter aerogenes: characterization and acute toxicity assessments. Mater Sci Eng C Mater Biol Appl. 2017;73:220-224.

85. Abbasi Aval N, Pirayesh Islamian J, Hatamian M, Arabfirouzjaei M, Javadpour J, Rashidi MR. Doxorubicin loaded large-pore mesoporous hydroxyapatite coated superparamagnetic $\mathrm{Fe}_{3} \mathrm{O}_{4}$ nanoparticles for cancer treatment. Int J Pharm. 2016;509(1-2):159-167.

86. Guo X, Gough J, Xiao P. Electrophoretic deposition of hydroxyapatite coating on $\mathrm{Fe} \mathrm{Cr}$ alloy and analysis of human osteoblastic cellular response. J Biomed Mater Res A. 2007;80:24-33.

87. Ansar EB, Ajeesh M, Yokogawa Y, Wunderlich W, Varma HK. Synthesis and characterization of iron oxide embedded hydroxyapatite bioceramics. J Am Ceram Soc. 2012;95(9):2695-2699.

88. Cui X, Green MA, Blower PJ, et al. $\mathrm{Al}(\mathrm{OH})_{3}$ facilitated synthesis of water-soluble, magnetic, radiolabelled and fluorescent hydroxyapatite nanoparticles. Chem Commun (Camb). 2015;51(45):9332-9335.

89. Lin K, Chen L, Liu P, et al. Hollow magnetic hydroxyapatite microspheres with hierarchically mesoporous microstructure for $\mathrm{pH}$ responsive drug delivery. CrystEngComm. 2013;15(15):2999-3008.

90. Boda SK, Anupama AV, Basu B, Sahoo B. Structural and magnetic phase transformations of hydroxyapatite magnetite composites under inert and ambient sintering atmospheres. J Phys Chem C. 2015;119(2): 6539-6555.

91. Place ES, Evans ND, Stevens MM. Complexity in biomaterials for tissue engineering. Nat Mater. 2009;8(6):457-470.

92. Panseri S, Russo A, Sartori M, et al. Modifying bone scaffold architecture in vivo with permanent magnets to facilitate fixation of magnetic scaffolds. Bone. 2013;56(2):432-439.

93. Liu M, Zhou G, Hou Y, et al. Effect of nano-hydroxyapatitecoated magnetic nanoparticles on axonal guidance growth of rat dorsal root ganglion neurons. J Biomed Mater Res A. 2015;103(9): 3066-3071.

94. Tran N, Webster TJ. Understanding magnetic nanoparticle osteoblast receptor-mediated endocytosis using experiments and modeling. Nanotechnology. 2013;24(18):185102.

95. Tran N, Hall D, Webster TJ. Mechanisms of enhanced osteoblast gene expression in the presence of hydroxyapatite coated iron oxide magnetic nanoparticles. Nanotechnology. 2012;23(45):455104.

96. Adams CF, Pickard MR, Chari DM. Magnetic nanoparticle mediated transfection of neural stem cell suspension cultures is enhanced by applied oscillating magnetic fields. Nanomedicine. 2013;9(6): 737-741.

97. Bock N, Riminucci A, Dionigi C, et al. A novel route in bone tissue engineering: magnetic biomimetic scaffolds. Acta Biomater. 2010;6(3): 786-796.

98. Tampieri A, Landi E, Valentini F, et al. A conceptually new type of bio-hybrid scaffold for bone regeneration. Nanotechnology. 2011; 22(1):015104.

99. Russo A, Shelyakova T, Casino D, et al. A new approach to scaffold fixation by magnetic forces: application to large osteochondral defects. Med Eng Phys. 2012;34(9):1287-1293.

100. Russo A, Bianchi M, Sartori M, et al. Bone regeneration in a rabbit critical femoral defect by means of magnetic hydroxyapatite macroporous scaffolds. J Biomed Mater Res B Appl Biomater. Epub 2017 Feb 15.

101. Zhu Y, Yang Q, Yang M, et al. Protein corona of magnetic hydroxyapatite scaffold improves cell proliferation via activation of mitogenactivated protein kinase signaling pathway. ACS Nano. 2017; 11(4):3690-3704.

102. Chen F, Huang P, Zhu YJ, Wu J, Zhang CL, Cui DX. The photoluminescence, drug delivery and imaging properties of multifunctional $\mathrm{Eu}^{3+} / \mathrm{Gd}^{3+}$ dual-doped hydroxyapatite nanorods. Biomaterials. 2011; 32(34):9031-9039.

103. Pan J, Zhang J, Wang L, Wan D. Synthesis of iron oxide coated fluoridated $\mathrm{HAp} / \mathrm{Ln}^{3+}(\mathrm{Ln}=\mathrm{Eu}$ or $\mathrm{Tb})$ nanocomposites for biological applications. Chem Commun. 2014;50(90):14010-14012. 
104. Kamitakahara M, Ohtoshi N, Kawashita M, Ioku K. Spherical porous hydroxyapatite granules containing composites of magnetic and hydroxyapatite nanoparticles for the hyperthermia treatment of bone tumor. J Mater Sci Mater Med. 2016;27(5):93.

105. Mah C, Zolotukhin I, Fraites T, et al. Microsphere mediated delivery of recombinant AAV vectors in vitro and in vivo. Mol Ther. 2000;1: S239-S242.
106. Chen L, Mccrate JM, Lee JC, Li H. The role of surface charge on the uptake and biocompatibility of hydroxyapatite nanoparticles with osteoblast cells. Nanotechnology. 2011;22(10):105708.

107. Wu HC, Lin FH. Evaluation of magnetic-hydroxyapatite nanoparticles for gene delivery carrier. Biomed Eng Appl Basis Commun. 2010; 22(1):33-39.

\section{Publish your work in this journal}

The International Journal of Nanomedicine is an international, peerreviewed journal focusing on the application of nanotechnology in diagnostics, therapeutics, and drug delivery systems throughout the biomedical field. This journal is indexed on PubMed Central, MedLine, CAS, SciSearch ${ }^{\circledR}$, Current Contents ${ }^{\circledR} /$ Clinical Medicine,
Journal Citation Reports/Science Edition, EMBase, Scopus and the Elsevier Bibliographic databases. The manuscript management system is completely online and includes a very quick and fair peer-review system, which is all easy to use. Visit http://www.dovepress.com/ testimonials.php to read real quotes from published authors. 